Dept. of Animal Diseases,

Fac. of Vet. Med., Al-Baath Univ., Syria

\title{
USING GARLIC PASTE AS FEED ADDITIVE IN HIGH NUTRIENTS DENSITY BROILER DIETS ON PERFORMANCE AND BIOCHEMICAL PARAMETERS
}

(With 6 Tables)

\section{By \\ A.J. CHEKH SULIMAN; A.M. SUBAH* and S. AWA DALLAH**}

* Dept. of Animal Production, Fac. of Vet. Med., Al-Baath Univ., Syria. ** Dept. of Nutrition and Clinical Nutr., Fac. Vet. Med., Cairo Univ., Egypt.

(Received at 24/2/2011)

تأثير معجون الثوم كمضاف علفي في خلطات دجاج اللحم المرتفعة المستوى الأتواتئ

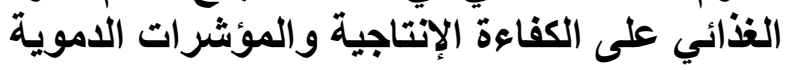

عبد الجبار الشيخ سليمان ، أحد مفبا صبح ، صبري عوض الله

أجريت تجربة لدر اسة إمكانية استخدام معجون الثوم كمضاف علفي إلى خلطات دجاج

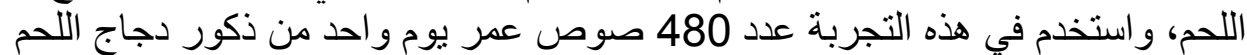

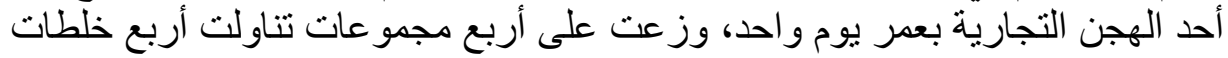

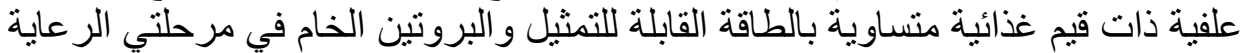

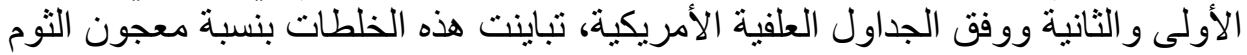

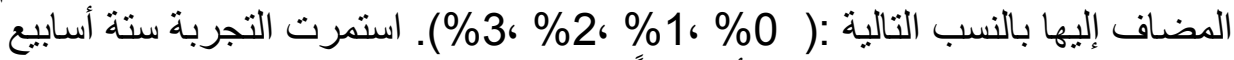

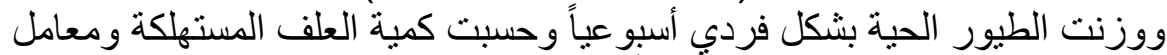

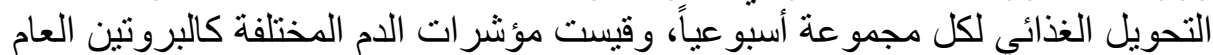
و ألبيومين الدم وسكر الدم والثحوم الثناثية وكولسترول الدام و البروتينات الثينات الثحمية العالية الثالية

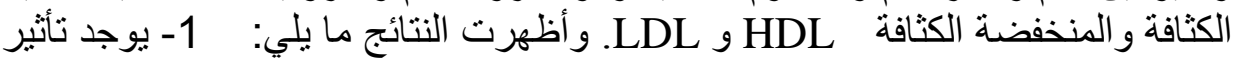
إيجابي لإضافة معجون الثوم في سر عة النمو إذ ازدادت بشكل معنوي على مستوى

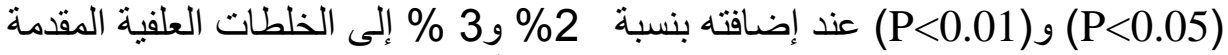

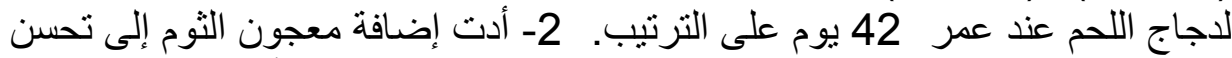
ملحوظ في معامل التحويل الغذائى، وحققت نسبة الإضافة 32 3.

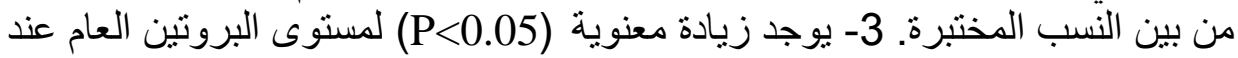

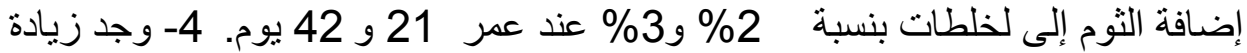

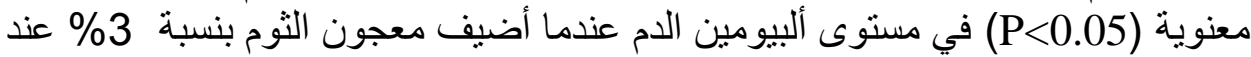

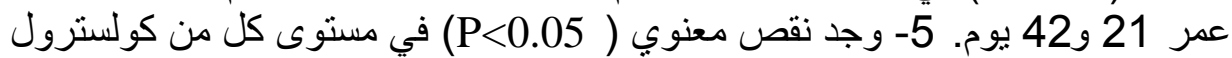

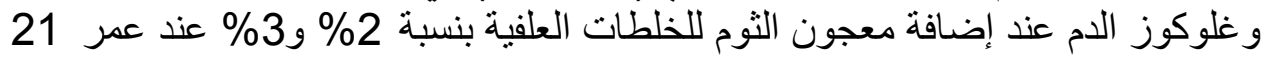




$$
\begin{aligned}
& \text { و } 42 \text { يوم. 6- انخفاض معنوي (P<0.05) للثحوم الثثلاثية و LDL عند إضافة معجون } \\
& \text { الثوم إلى الخلطات العلفية بنسبة 32\% عند عمر } 21 \text { و و42 يوم. }
\end{aligned}
$$

\section{SUMMARY}

A trial was carried out to study the possibility of using garlic paste as feed additive to high nutrients density broilers diets. Four hundred eighty one day-old male chicks of commerical meat line were used in the trial. The birds were distributed into four groups of 120 birds each and fed with isocaloric and isonitrogenous diets, containing different levels of tested garlic as follows: $0 \%, 1 \%, 2 \%, 3 \%$. The experiment lasted for 6 weeks. Live body weight and feed conversion ratios were weekly recorded. Estimate of serum biochemical parameters. Results showed as follows: There is a positive effect of adding garlic paste on the growth rate which significantly increased $(\mathrm{P}<0.05)$ and $(\mathrm{P}<0.01)$ when it was added to diets containing $3 \%$. It was also found a positive effect of adding garlic paste to diets on feed conversion ratio specially with $3 \%$ rate. There is significant increase $(\mathrm{P}<0.05)$ in total protein when garlic paste was added to diets in $3 \%$ and $2 \%$ rate at 21 and 42 days. There is significant increase $(\mathrm{P}<0.05)$ in Albumin when garlic paste was added to diets in $3 \%$ rate at 21 and 42 days. There is significant decrease $(\mathrm{P}<0.05)$ in serum cholesterol and glucose levels when garlic paste was added to diets in $3 \%$ and $2 \%$ rate at 21 and 42 days. There is significant decrease $(\mathrm{P}<0.05)$ in serum triglycerides levels and LDL when garlic paste was added to diets in $3 \%$ rate at 21 and 42 days.

Key words: Broilers, garlic paste, feed additives, biochemical parameters.

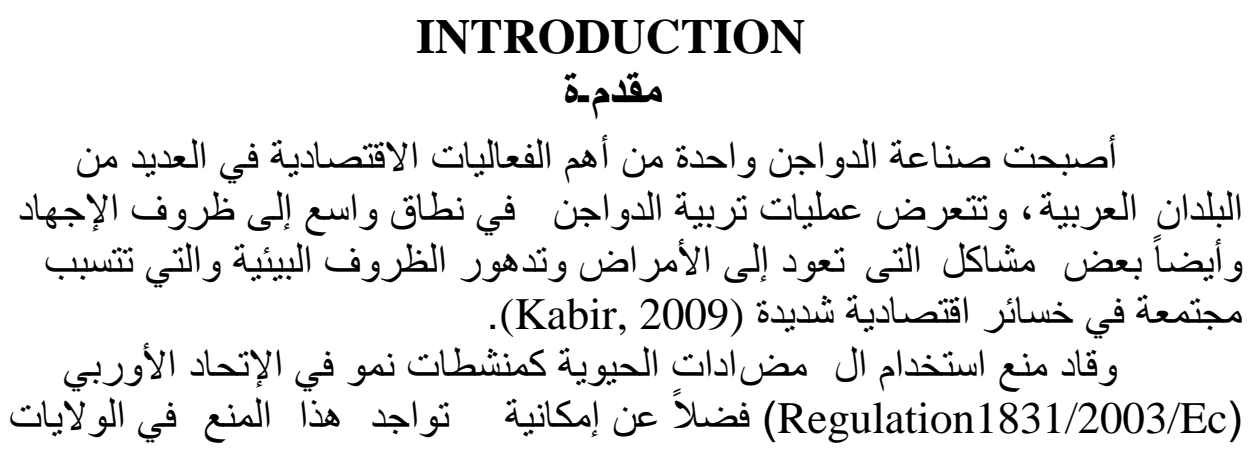


المتحدة الأمريكية إلى الاهتمام بإيجاد بدائل علفية طبيعية تدعم الإنتاج الحيو اني Ocak) 'et al., 2008)

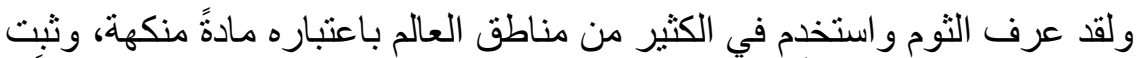

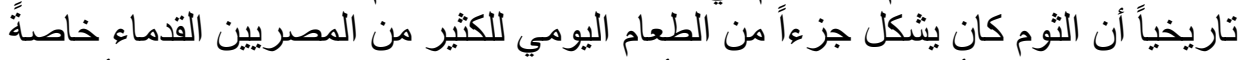

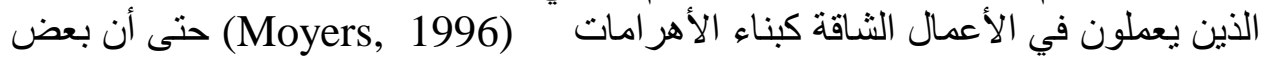

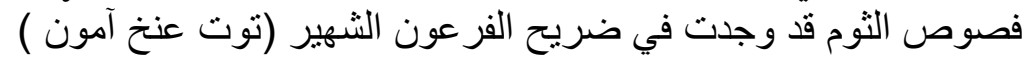

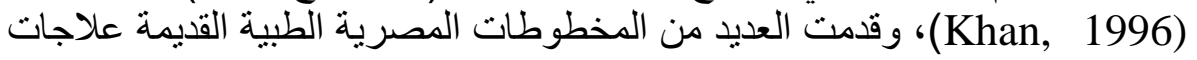

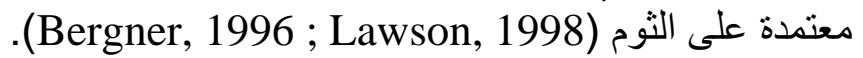

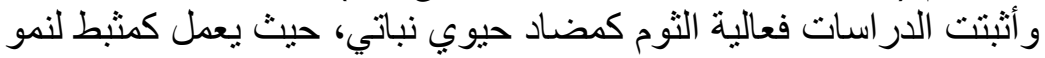

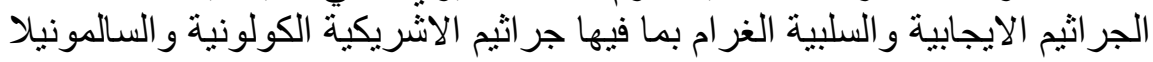

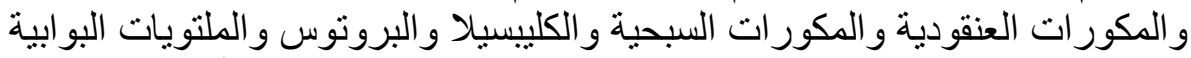
Reuter et al., 1996; Ankri and Mirelman, 1999) العلمية إلى إمكانية إضافة كلٍ من الثوم و/ أو البصل إلى خلطات دجاج التسمين البادئة

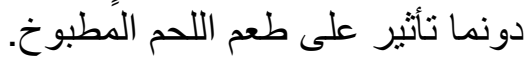

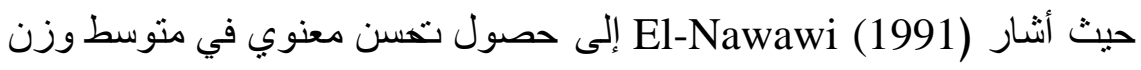

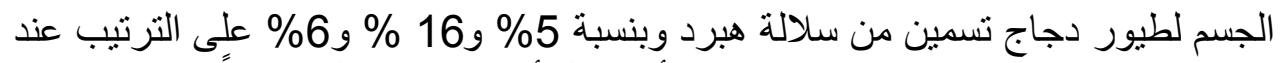

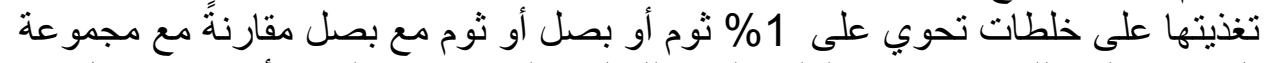

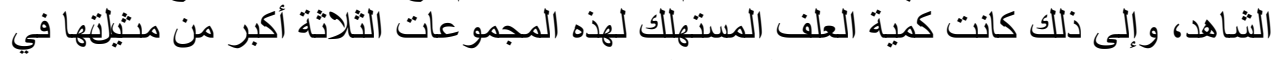

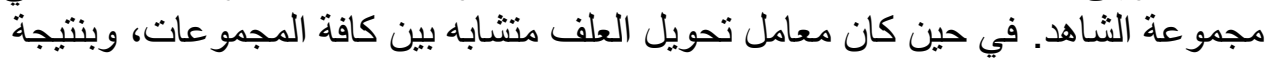
الدر اسة افترض البآحث أن الثوم يحرض معامل على النمو نتيجة تأثيره المشابه لتأثنير ات الغدة

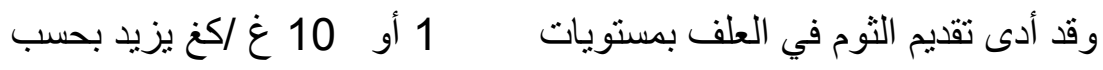

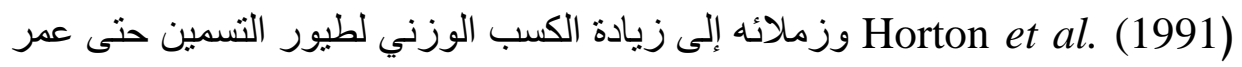

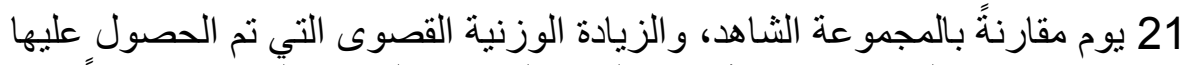

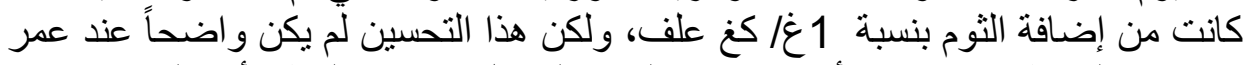

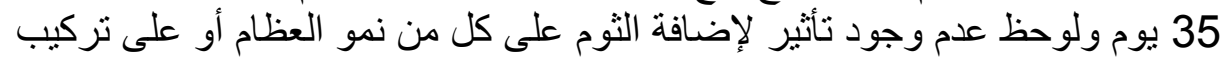

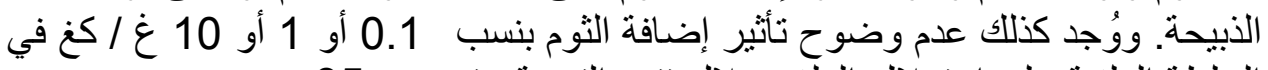
الخلطة العلفية على استهلاك العلف خلال فترة التربية حتى عمر 35 يوم.

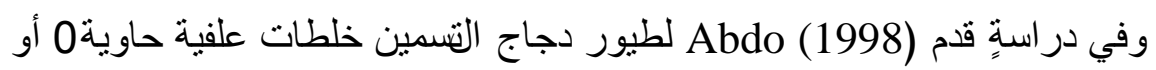
3 أو 6\% ثوم لمدة 3 أسابيع، ووجد فروقاً معنويةً بين المجمو عات الثناثة، وكاج وكان أفضل

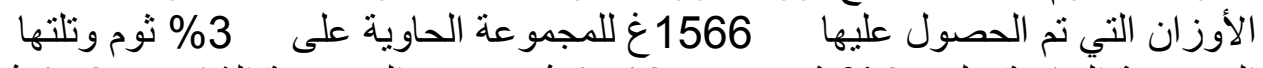

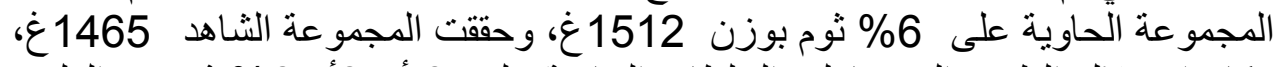

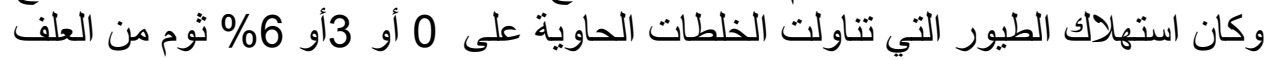

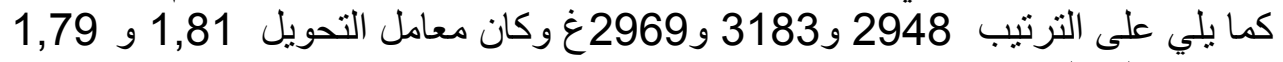
و1,61 على الترنيب. 


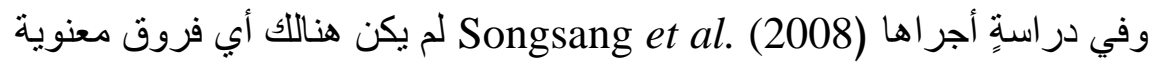

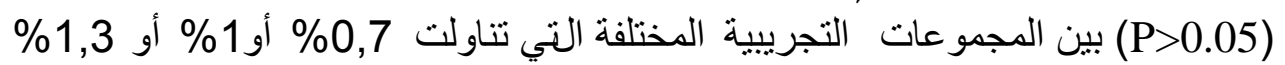

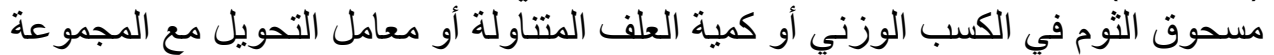

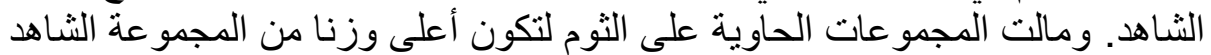

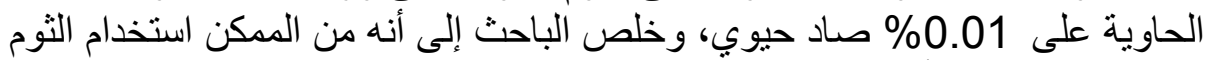
كنشط نمو ويمكن أن يحافظ على الكفاءة الإنتاجية.

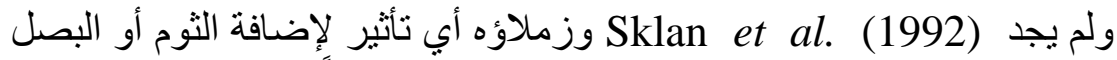

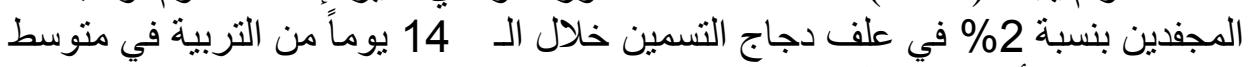
الكسب الوزني أو في معامل التحويل العلفي.

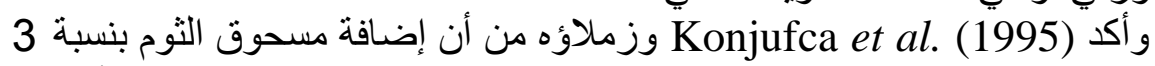
أو 4.5 أو 15 \% إلى الخلطات العلفية البادئة الكقدمة لطيور التسمين حتى عمر 2 أسبوع ليس لها تأثير على الكسب الوزني.

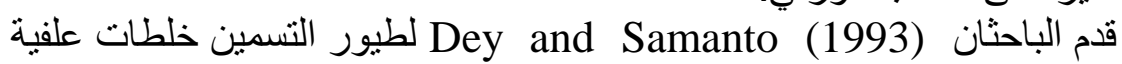

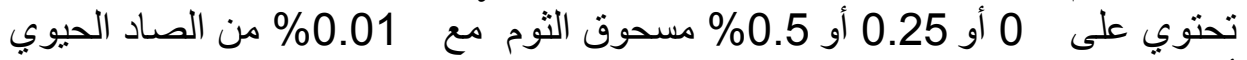

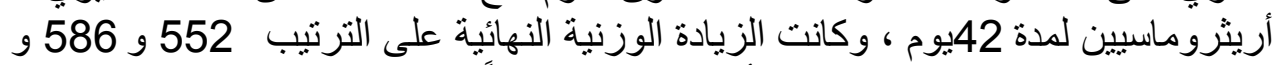
637 و 650غ، واستخلص الباحثان أن الثوم يلعب دور أ كمنثط نمو عند تقديمئه لطيور

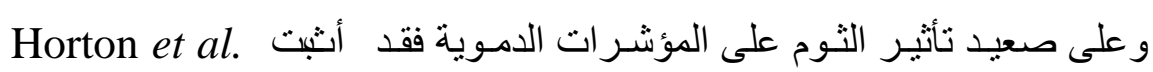

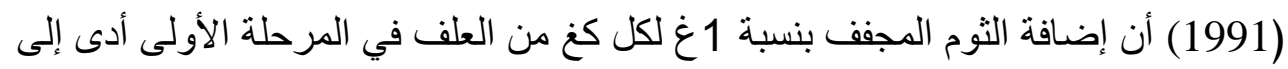

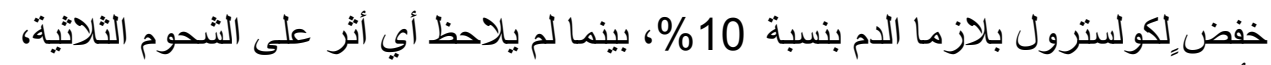

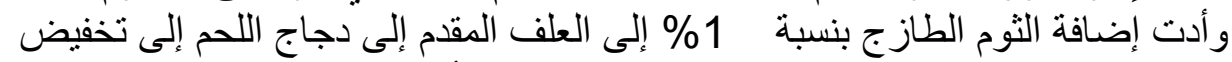

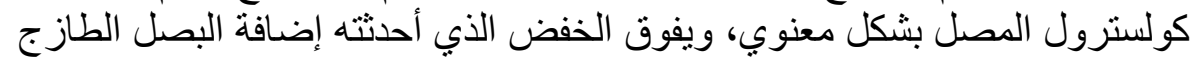
.Ayoub (1996)

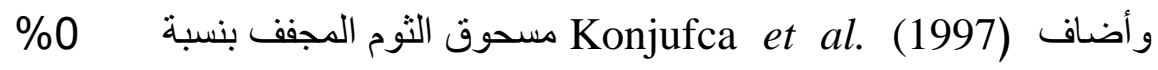

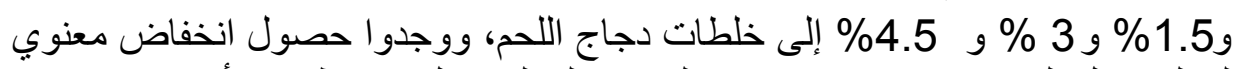

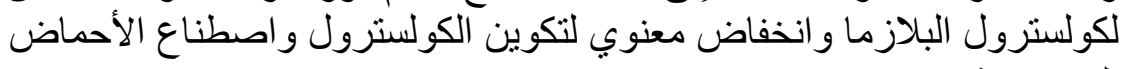

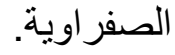

ووجد (Haq et al. أن لإضافة الثوم إلى علف الدجاج تخفيضاً معنوياً

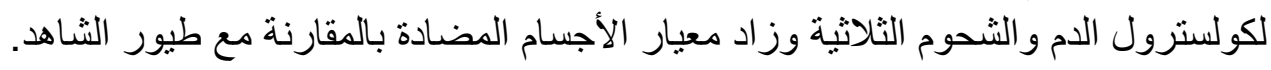

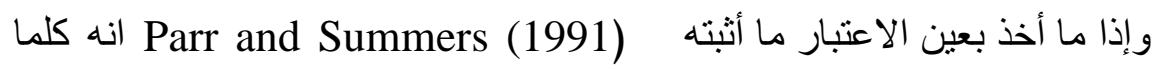

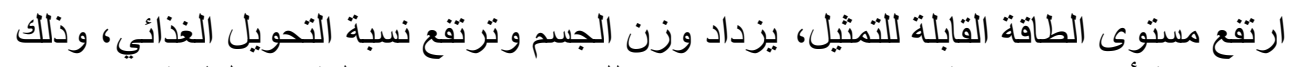

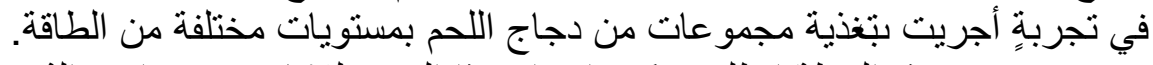

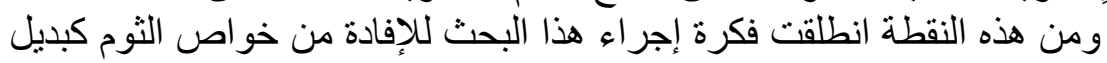
طبيعي لمنشطات النمو المعروفة كالصادات الحيوية والتي منع استخدامها في دول الإنحاد التحاد 
الأوربي وبعض دول المغرب العربي، ويشكل خياراً علاجياً عند نربية الاجاج العضوي الإبي الأجدى اقتصاديا كمنتج خاص بالإنصدير إلى دولى دول الاتحاد الأوربي.

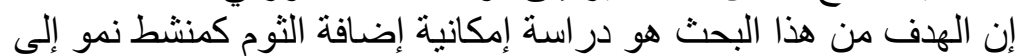

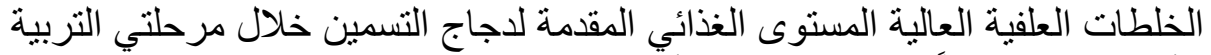

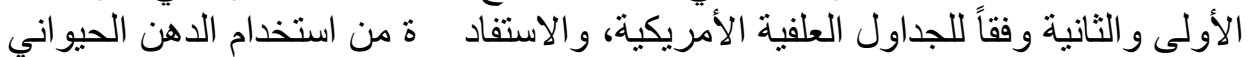

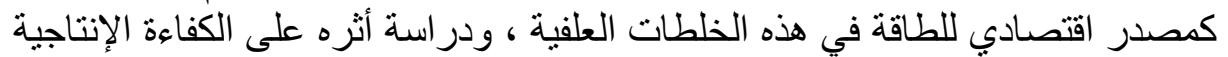
لهذا النوع من الدجاج و على المؤشر لهذات الدموية المختلفة.

\section{MATERIALS and METHODS مواد وطرائق البحث}

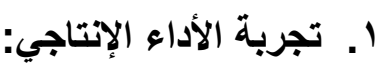

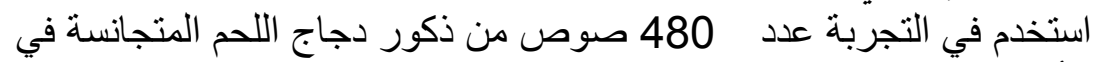

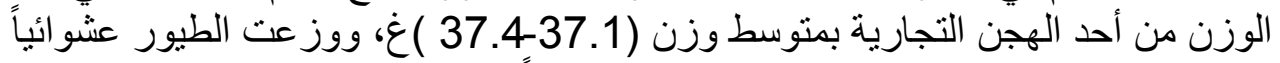

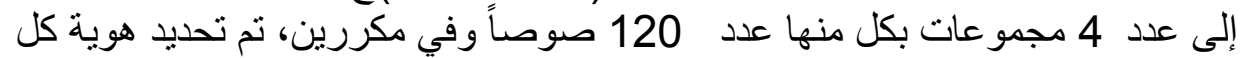

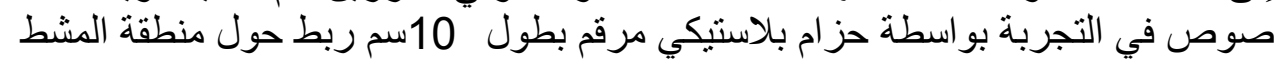
وتم تبديله مرتين حتى انتهاء التربية. وقد زودت أقسام حظيرة التجاربة التبربة بالمعالف و المشارب اللازمة في مر احل

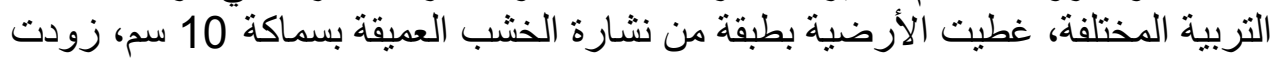

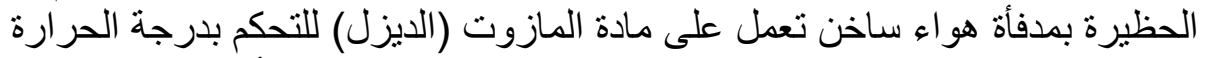

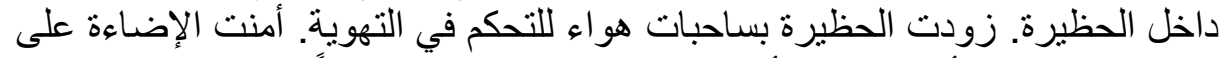

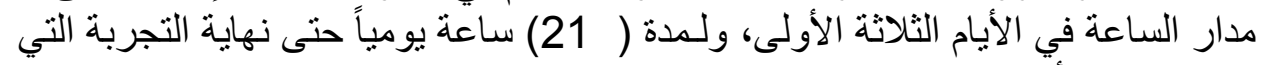
استمرت ستة أسبابيع.

$$
\begin{aligned}
& \text { تم تحصين كافة طيور التجربة وفقاً لجدول التحصين التالي: } \\
& \text { اللقاح المقدم }
\end{aligned}
$$

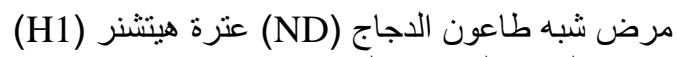

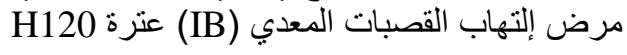

لقاح معطل لمرض شبه طاعون الدجاج الدجاج (ND)

مرض شبه طاعون الدجاج (ND) عترة كلون./ داعم/ المطاب (1BD)

قسمت فترة التربية إلى مرحلتين وفقاً للاحتياجات الغذائية المذكورة في

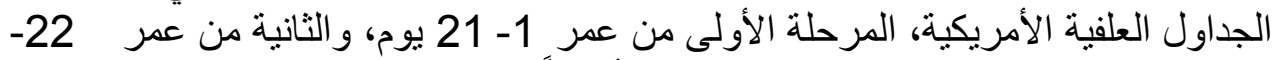

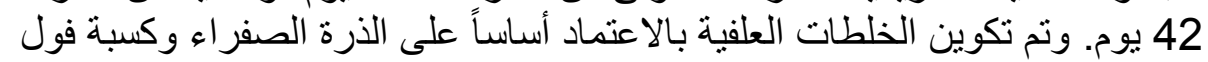

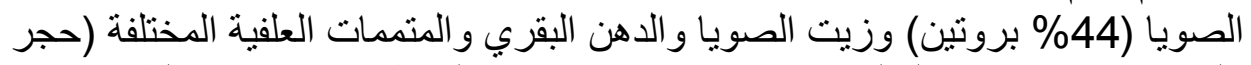

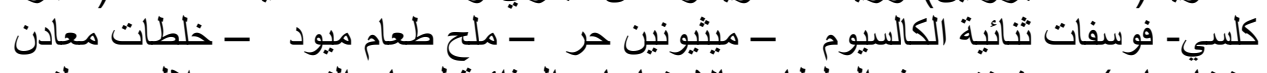
وفيتامينات) بحيث تفي هذه الخلطات بالاحتياجات الغذائية لاجاج التسمين، خلال مرحلتي 
التربية الأولى والثانية للتجربة. الجدول رقم ( 1) يبين تركيب الخلطات العلفية لمر احل

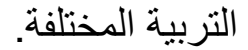

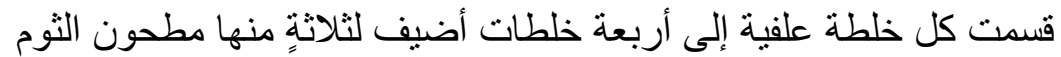

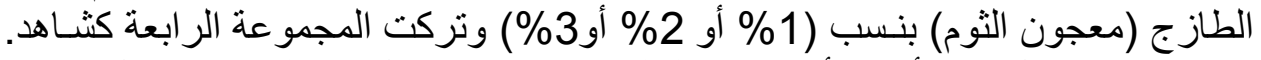

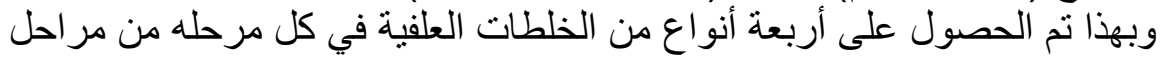

وتم تحضير معجون الثوم من فرم بصلة النبات كاملةً بفر امة لحم بدوية مركبة

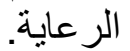

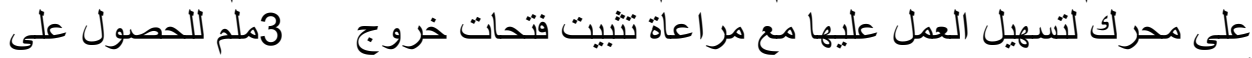

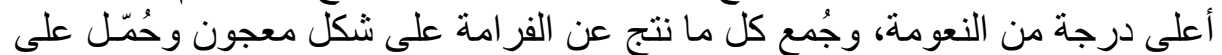

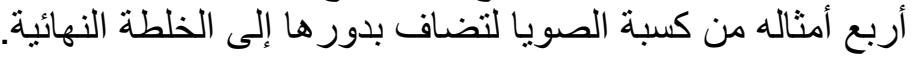

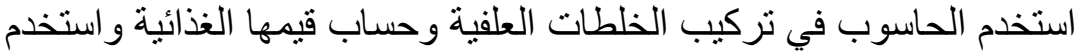

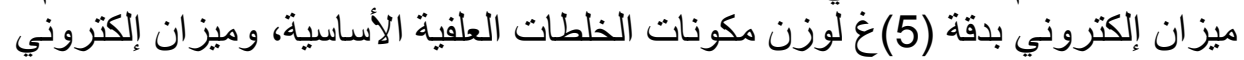

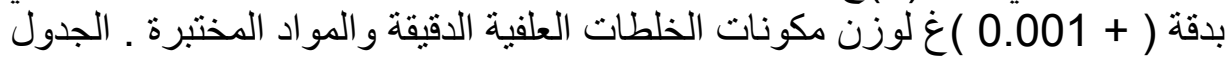
(2) يبين تحليل الخلطات العلفية خلال مرحلتي التربية المقترحة.

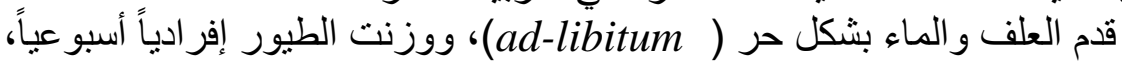

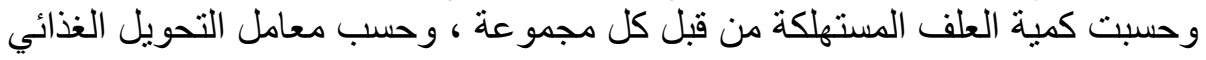

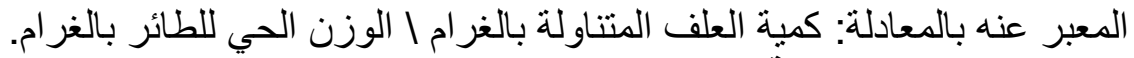
r. بلحيل الخلطات العلفية:

حلت الخلطات العلفية مخبرياً في مخبر تحليل الأغذية والبحث العلمى فئ في كلية

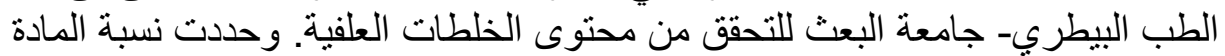

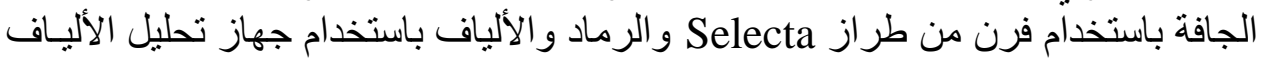

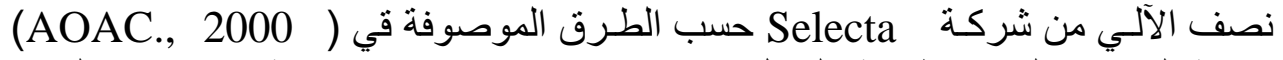
ونسبة البروتين الخام (بطريقة كلداهل) وباستخدام جهاز من صنع شركة

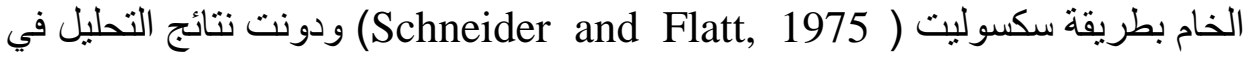

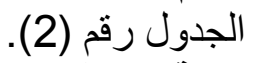

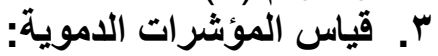

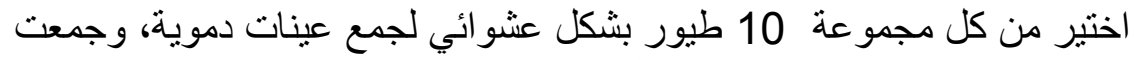

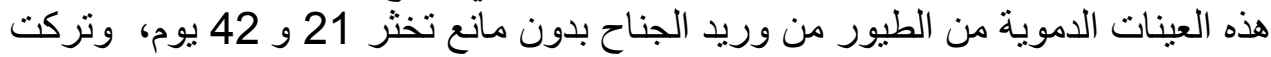

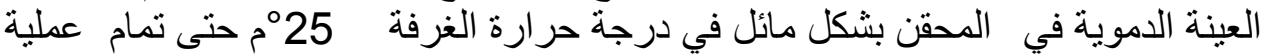

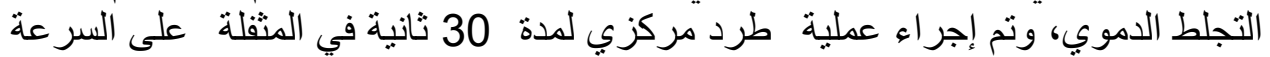

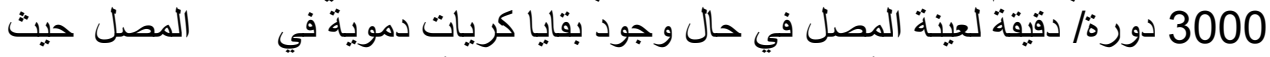

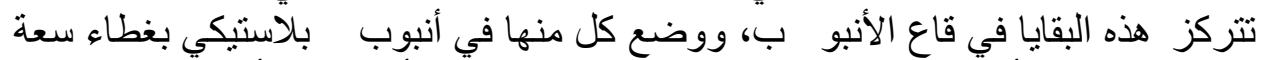

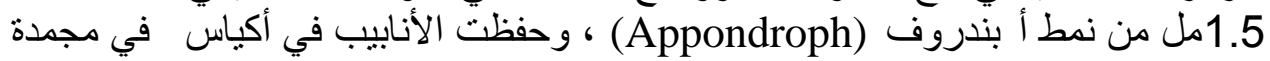

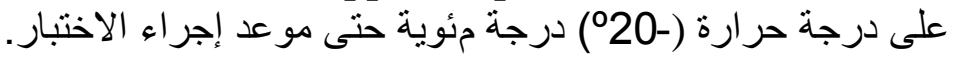

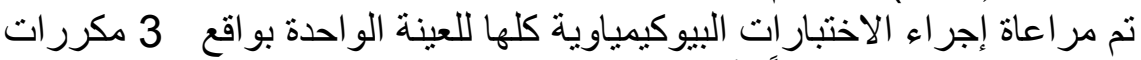

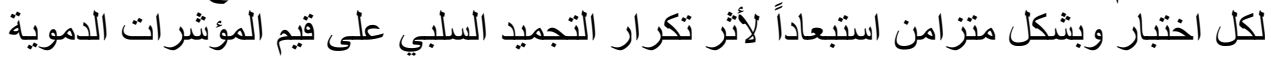

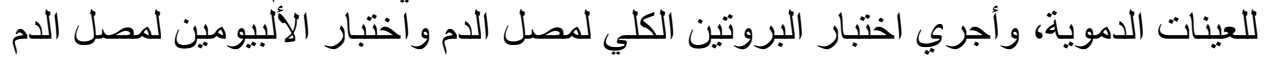


و اختبار سكر الدم و الثحوم الثلاثية و الكولسترول و البروتينات الثحمية العالية الكثافة

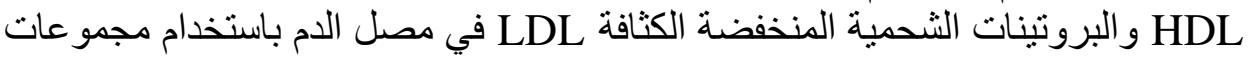

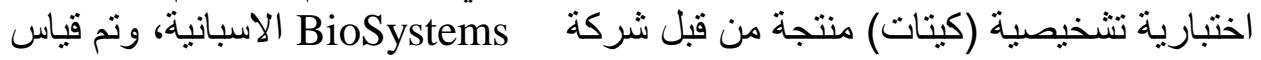
Spectronic Instrument, امتصاصية العينات باستخدام جهاز مقياس الطيف الضئئي

.Model.2001/4

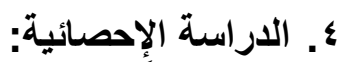

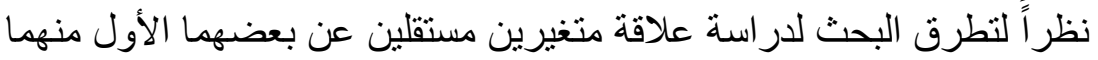

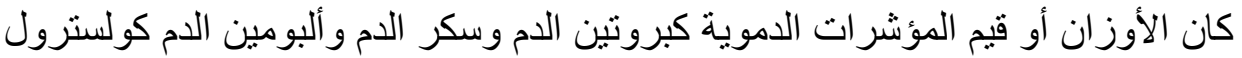

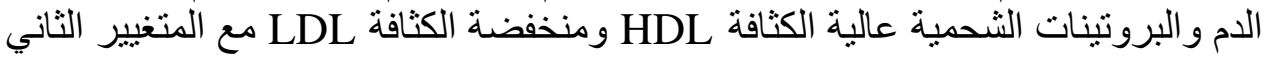

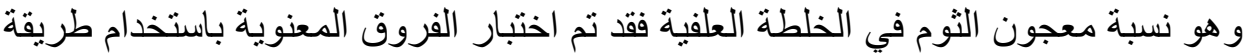

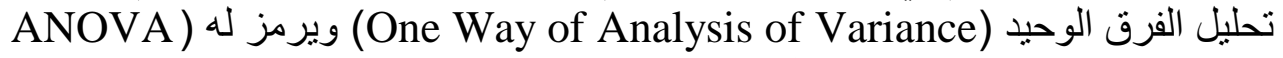

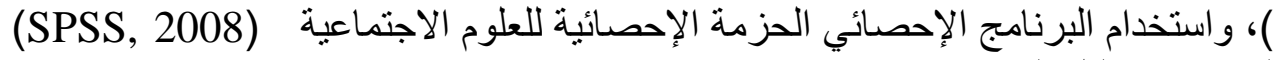
لمقارنة وتحليل النتائج الإحصائية.

\section{RESULTS}

النتائسج

جدول رقم 1 : نركيب الخلطات العلفية المستخدمة في مرحلتي الرعاية.

\begin{tabular}{|c|c|c|}
\hline \multicolumn{2}{|c|}{ مر احل التربية } & \multirow{2}{*}{ الجو اد العلفية \% } \\
\hline 42-22 42يوم & 21-1 يوم & \\
\hline 51.86 & 46 & ذرة صفراء \\
\hline 38 & 44.1 & كسبة فول الصويا \\
\hline 4.2 & 4 & زيت صويا \\
\hline 2.1 & 2 & دهــن بقري \\
\hline 2.2 & 2.2 & فوسفات ثنائية الكالسبوم \\
\hline 0.7 & 0.7 & كربونات الكالسيوم \\
\hline 0.16 & 0.2 & ميثيونين حر \\
\hline 0.4 & 0.4 & ملح طعام ميود \\
\hline 0.08 & 0.1 & كلوريد الكولين \\
\hline 0.1 & 0.1 & خلطة الفيتامينات* \\
\hline 0.1 & 0.1 & خلطة المعادن * \\
\hline 0.05 & 0.05 & مضاد كو كسيديا \\
\hline 0.05 & 0.05 & رابط سموم فطرية \\
\hline 100 & 100 & المجموع ال الموع \\
\hline
\end{tabular}

* كل 1كغ من العلف الجاهز يحتوي على الفيتامينات و والمعادن النادرة اللازمة وفقاً للاحتياجات الأميركية

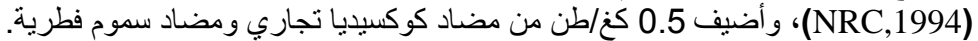

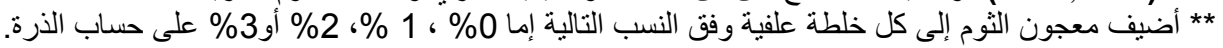
جدول رقم 2 : تحليل الخلطات العلفية وقيمها الغذائية

\begin{tabular}{|c|c|c|}
\hline \multicolumn{2}{|c|}{ مر احل التربية } & \multirow{2}{*}{ المكونات الغذائية } \\
\hline 42-22 يوم & 21-1 يوم & \\
\hline 3162 & 3078 & الطاقة القابلة للتنثيل كيلو كالوري/كغ \\
\hline
\end{tabular}


Assiut Vet. Med. J. Vol. 57 No. 129 April 2011

\begin{tabular}{|c|c|c|}
\hline 21.22 & 23.43 & البروتين الخام \% \\
\hline 149.05 & 131.37 & الطاقة/البروتين * \\
\hline 1.16 & 1.31 & اللايسين \% \\
\hline 0.49 & 0.55 & الميثيونين \% \\
\hline 0.83 & 0.93 & المثيونين + السيستين \% \\
\hline 0.31 & 0.35 & التربتوفان \% \\
\hline 0.86 & 0.88 & الكالسيوم \% \\
\hline 0.59 & 0.61 & الفوسفور الكلي \% \\
\hline 0.56 & 0.57 & الفوسفور المتاح \% \\
\hline 0.17 & 0.17 & الصوديوم \% \\
\hline 0.3 & 0.3 & الكلور \% \\
\hline 3.53 & 3.32 & حمض اللينوليك \% \\
\hline 3.8 & 4.1 & الألياف \% \\
\hline
\end{tabular}

* الطاقة/البروتين: هي نسبة تعد مؤشرًا لرفع المكونات الغذائية عند زيادة تركيز الطاقة والعكس صحيح عند انخفاضها.

التحليل المخبري للخلطات العلفية

\begin{tabular}{|c|c|c|}
\hline \multicolumn{2}{|c|}{ مر احل التربية } & \multirow{2}{*}{ المكون الغذائي } \\
\hline 42-22 يوم & 21-1 يوم & \\
\hline 21.94 & 23.03 & البروتين الخام \% \\
\hline 8.3 & 7.73 & نسبة الدهون الخام \% \\
\hline 5.84 & 6.6 & نسبة الرماد \% \\
\hline 88.23 & 87.48 & نسبة المادة الجافة \% \\
\hline 3.44 & 3.92 & نسبة الألياف \% \\
\hline
\end{tabular}


Assiut Vet. Med. J. Vol. 57 No. 129 April 2011 
الجدول رقم 3 : متوسط أوزان طيور المجموعات التي غذيت على خلطات علفية حاوية على نسب مختلفة من الثوم خلال فترة التجربة + الانحر اف المعياري ونسبةً إلى الأوزان الأسبو عية لطيور مجمو عة الثـاهد.

\begin{tabular}{|c|c|c|c|c|c|c|c|c|c|c|c|}
\hline \multicolumn{3}{|c|}{ 3\% ثـوم } & \multicolumn{3}{|c|}{ 2\% ثــــم } & \multicolumn{3}{|c|}{1 \% ثـوم } & \multicolumn{2}{|c|}{ شـــــاهد } & \multirow{2}{*}{ المجنغوعة } \\
\hline \multirow{2}{*}{ نسبةً إلى } & \multirow[b]{2}{*}{ الانحرياري } & \multirow{2}{*}{ الوزن } & \multirow{2}{*}{ نسبةً إلى الثاهد } & \multirow{2}{*}{ الالحعراف } & \multirow{2}{*}{ الوزن } & \multirow{2}{*}{ نسبةً إلى } & \multirow{2}{*}{ الانحر اف } & \multirow{2}{*}{ متوسط } & \multirow{2}{*}{ الالحياري } & \multirow{2}{*}{ 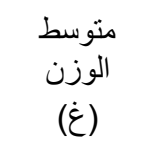 } & \\
\hline & & & & & & & & & & & الأسبوع \\
\hline 1.04 & 18.47 & $\mathrm{~b}_{159.25}$ & 1.05 & 19.01 & ${ }^{b} 160.67$ & 1.04 & 16.51 & ${ }^{b} 159.22$ & 20.21 & ${ }^{a} 153.39$ & الأول \\
\hline 1.06 & 49.96 & ${ }^{\mathrm{B}} 444.46$ & 1.05 & 51.68 & ${ }^{\mathrm{B}} 441.47$ & 1.03 & 47.02 & 431.44 & 56.97 & ${ }^{A} 419.02$ & الثاني \\
\hline 1.05 & 102.23 & ${ }^{\mathrm{Bb}} 901.99$ & 1.03 & 96.4 & 882.13 & 1.01 & 105.63 & ${ }^{\mathrm{a}} 869.06$ & 105.62 & ${ }^{A} 857.85$ & الثالث \\
\hline 1.05 & 128.87 & $\mathrm{~B}_{1458.52}$ & 1.03 & 160.3 & 1434.6 & 1.02 & 142.21 & 1423.39 & 176.69 & $\mathrm{~A}_{1391.12}$ & الر ابع \\
\hline 1.04 & 278.38 & ${ }^{\mathrm{b}} 2150.44$ & 1.03 & 202.54 & 2133.47 & 1.03 & 224.5 & 2130.52 & 263.53 & ${ }^{\mathrm{a}} 2068.45$ & الخامس \\
\hline 1.04 & 277.32 & ${ }^{\mathrm{b}} 2636.22$ & 1.02 & 296.28 & 2600.47 & 1.02 & 303.86 & 2599.48 & 315.17 & ${ }^{a} 2539.57$ & السادس \\
\hline
\end{tabular}

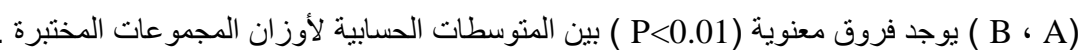

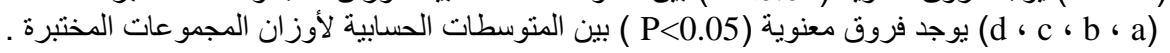


الجدول رقم 4 : معامل التحويل الغذائي التراكمي وكمية العلف الأسبو عية التراكمية المستهلكة لمجموعات الطيور المتناولة لخلطات علفية حاوية على الكي

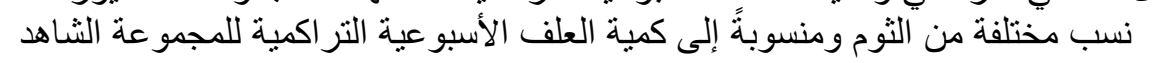

\begin{tabular}{|c|c|c|c|c|c|c|c|c|c|c|c|}
\hline \multicolumn{3}{|c|}{ 3\% ثــوم } & \multicolumn{3}{|c|}{ 2\% ثــوم } & \multicolumn{3}{|c|}{1 \% ثـوم } & \multicolumn{2}{|c|}{ شـــاهد } & المجمو عة \\
\hline كمية العلى & التراكي & التحويل & كمية العلف & التراكي & التحويل & كمبة العلف & التراكمي & التحعويل & التراكي & التحويل & الأسبوع \\
\hline 0.94 & 174.9 & 1.10 & 0.99 & 184.0 & 1.15 & 0.99 & 183.94 & 1.16 & 186.61 & 1.22 & الأول \\
\hline 0.96 & 531.9 & 1.20 & 1.05 & 581.5 & 1.32 & 1.04 & 576.28 & 1.34 & 555.69 & 1.33 & الثاني \\
\hline 0.98 & 1155.5 & 1.28 & 1.01 & 1192.3 & 1.35 & 1.02 & 1199.78 & 1.38 & 1180.47 & 1.38 & الثالث \\
\hline 0.99 & 2056.8 & 1.41 & 0.99 & 2056.5 & 1.43 & 1.04 & 2161.67 & 1.52 & 2083.00 & 1.50 & الرابع \\
\hline 0.98 & 3228.8 & 1.50 & 1.02 & 3340.8 & 1.57 & 1.03 & 3376.15 & 1.58 & 3285.95 & 1.59 & الخامس \\
\hline 0.98 & 4200.4 & 1.59 & 1.01 & 4321.1 & 1.66 & 1.02 & 4332.5 & 1.67 & 4268.4 & 1.68 & السادس \\
\hline
\end{tabular}


Assiut Vet. Med. J. Vol. 57 No. 129 April 2011

الجدول رقم 5 : منتوسطات قيم مؤشر ات الدم البيوكيمياوية المختلفة بعدر 21 يوم في التجربة الثانية.

\begin{tabular}{|c|c|c|c|c|c|c|c|c|c|c|c|c|}
\hline \multicolumn{3}{|c|}{ 3\% ثــوم } & \multicolumn{3}{|c|}{ 2\% ثـــوم } & \multicolumn{3}{|c|}{1 \% ثــوم } & \multicolumn{2}{|c|}{ شــــاهد } & & المجمو عة \\
\hline نسبة إلى & الانحر افياري & القيمة & نسبة إلى & الانحر اف & القيمة & إلىبة & الانحر اف & القيمة & الانحراف & القيمة & الو احدة & الدم البيوكيمياوية \\
\hline 1.22 & 4.04 & ${ }^{B} 39.87$ & 1.14 & 5.44 & ${ }^{b} 37.25$ & 1.10 & 3.41 & 36.04 & 2.09 & $\underset{\mathrm{Aa}}{32.63}$ & غ ال & بروتين الدم \\
\hline 1.29 & 3.87 & b 18.34 & 1.25 & 4.07 & 17.68 & 1.18 & 3.39 & 16.66 & 3.61 & $\mathrm{a}_{14.17}$ & غال & الألبو مين \\
\hline 0.88 & 56.25 & 251.34 & 0.9 & 74.15 & 256.55 & 0.98 & 86.82 & 278.83 & 47.73 & 284.17 & ملغ/دل & سكر الدم \\
\hline 0.86 & 12.72 & ${ }^{\mathrm{b}} 78.9$ & 0.9 & 10.97 & 82.84 & 0.93 & 11.65 & 85.47 & 6.71 & ${ }^{\mathrm{a}} 91.82$ & ملغ/دل & الثحوم الثلاثية \\
\hline 0.91 & 14.29 & 126.79 & 0.94 & 12.06 & 130.05 & 0.95 & 13.19 & 132.46 & 15.69 & 138.82 & ملغ/دل & الكولسترول \\
\hline 1.11 & 10.89 & 98.38 & 1.09 & 15.41 & 96.53 & 1.05 & 16.52 & 92.7 & 9.86 & 88.55 & ملغ/دل & 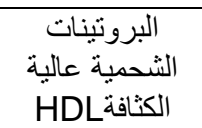 \\
\hline 0.85 & 18.33 & ${ }^{b} 105.18$ & 0.90 & 12.97 & 111.84 & 0.91 & 11.31 & 113 & 11.25 & $\mathrm{a}_{124}$ & ملغ/دل & 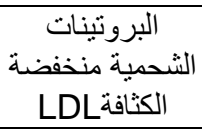 \\
\hline
\end{tabular}

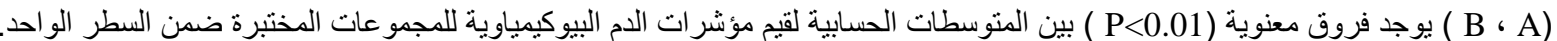

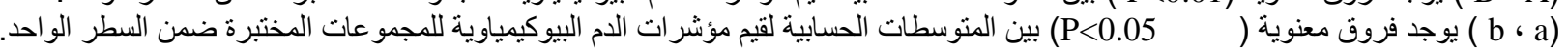




\section{Assiut Vet. Med. J. Vol. 57 No. 129 April 2011}

الجدول رقم 6 : متوسطات قيم مؤشرات الدم البيوكيمياوية المختلفة بعمر 42 يوم في التجربة الثانية.

\begin{tabular}{|c|c|c|c|c|c|c|c|c|c|c|c|c|}
\hline \multicolumn{3}{|c|}{ 3\% نـــــم } & \multicolumn{3}{|c|}{ 2\% ثــوم } & \multicolumn{3}{|c|}{1 \% ثــوم } & \multicolumn{2}{|c|}{ شــاهد } & & \multirow{2}{*}{ 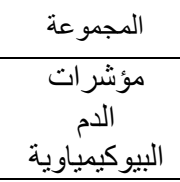 } \\
\hline نشبة إلى & الالانحراف & القيمة & الثسبة & المعياري & القيمة & نسبة إلى الثاهد & المعياري & القيمة & المعياري & القيمة & الواحدة & \\
\hline 1.13 & 3.09 & ${ }^{B} 33.76$ & 1.12 & 3.31 & $\mathrm{~b}_{33.48}$ & 1.05 & 2.73 & 31.42 & 1.99 & ${ }^{\mathrm{Aa}} 29.92$ & غال & بروتين الدم \\
\hline 1.13 & 1.99 & ${ }^{b} 21.37$ & 1.13 & 3.17 & ${ }^{b} 21.3$ & 1.06 & 2.12 & 20.1 & 2.58 & $\mathrm{a}_{18.91}$ & غال & الألبو مين \\
\hline 0.88 & 28.95 & ${ }^{b} 222.01$ & 0.9 & 25.51 & ${ }^{b} 228.61$ & 0.94 & 22.13 & 238.63 & 29.09 & ${ }^{\mathrm{a}} 253.67$ & ملغ/دل & سكر الدم \\
\hline 0.76 & 9.3 & ${ }^{\mathrm{Bd}} 41.7$ & 0.79 & 9.04 & $\mathrm{bd}_{43.59}$ & 0.95 & 9.49 & ${ }^{\mathrm{c}} 52.19$ & 8.94 & ${ }^{A a} 54.87$ & ملغ/دل & الثحوم الثلاثية \\
\hline 0.83 & 17.63 & ${ }^{B} 111.06$ & 0.84 & 18.74 & ${ }^{b} 112.38$ & 0.88 & 20.84 & 118.57 & 11.76 & ${ }^{\mathrm{Aa}} 134.47$ & ملغ/دل & الكولسترول \\
\hline 1.04 & 4.15 & 92.27 & 1.03 & 4.31 & 91.43 & 1.01 & 5.38 & 89.96 & 5.19 & 89.07 & ملغ/دل & 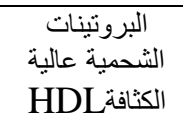 \\
\hline 0.85 & 9.63 & ${ }^{\mathrm{Bb}} 96.55$ & 0.96 & 6.94 & ${ }^{a} 108.76$ & 0.99 & 9.93 & ${ }^{a} 111.99$ & 9.55 & $\mathrm{~A}_{113.2}$ & ملغ/دل & 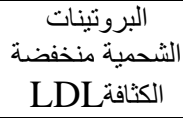 \\
\hline
\end{tabular}

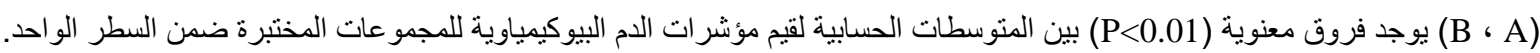

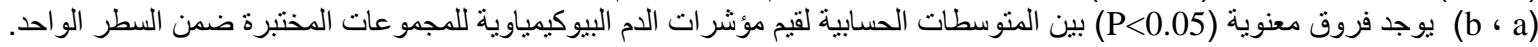


Assiut Vet. Med. J. Vol. 57 No. 129 April 2011 


\section{DISCUSSION \\ المناقشـة}

يبين الجدول رقم ( 3) متوسطات الأوزان الأسبوعية للطيور المتناولة لخلطات

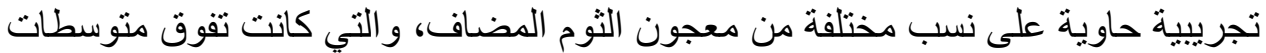

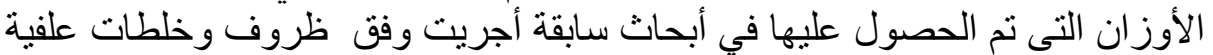

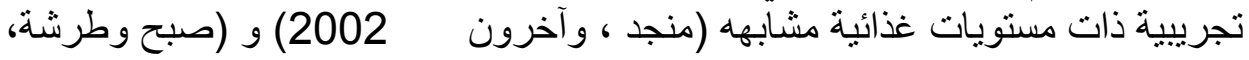

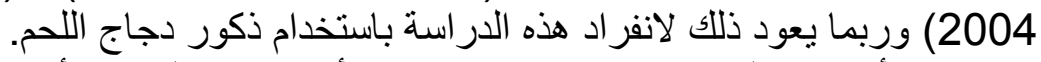

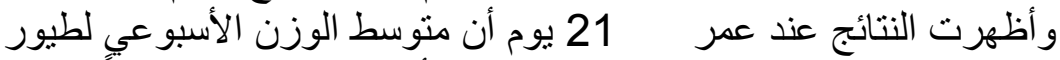

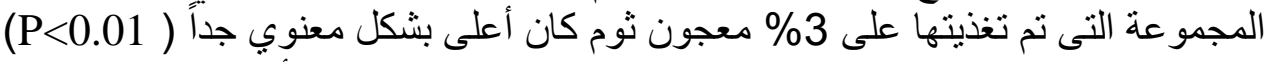

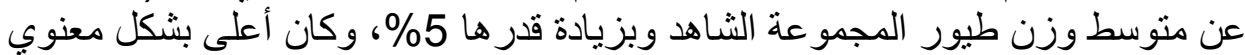

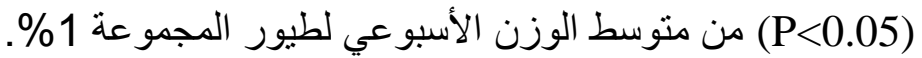

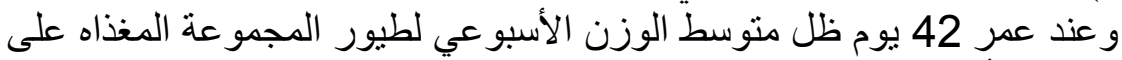

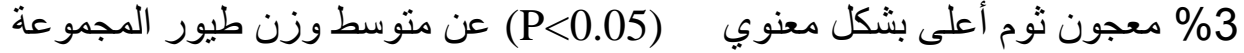

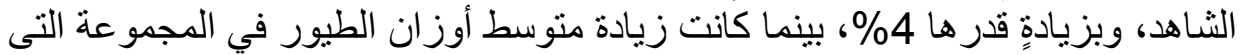

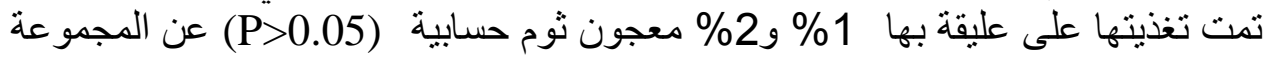
الثاهد وبنسبة 2\% لكلا المجمو عتين.

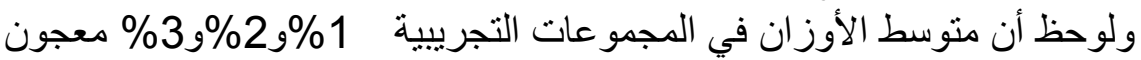

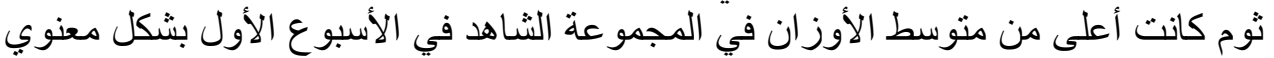
. $(\mathrm{P}<0.05)$

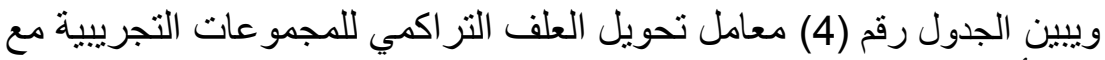

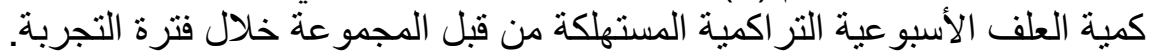

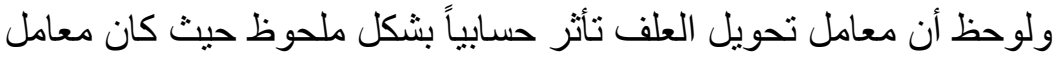

التحويل الغذائى عند عمر 21 يوم في المجمو عات التي تناولت الثوم بنسب على الترتيب 1.28 و 1.35 بينما كانت 1.38 يوم في المجموعة الثناهد، و وعند عمر 42 يوم

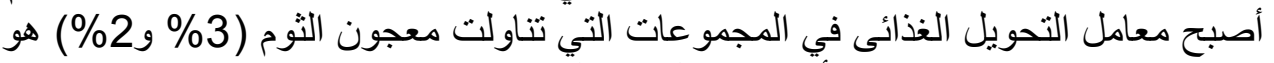

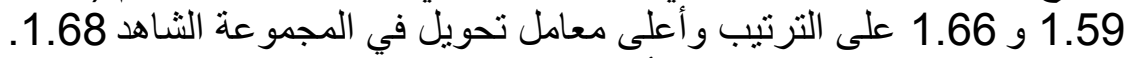
وتتفق هذه النتائج مع ما أنثار إليه

معنوي (P<0.05) في متوسط وزن الجسم لطيور تسمين من هجين هبرد وبنسبة \%

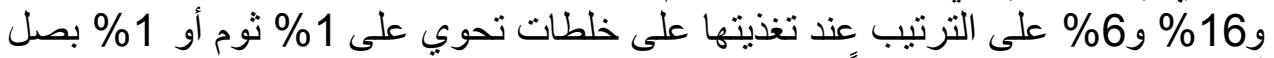

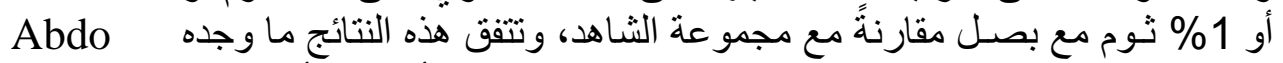

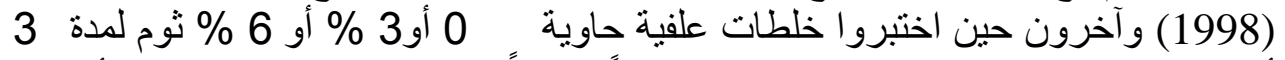

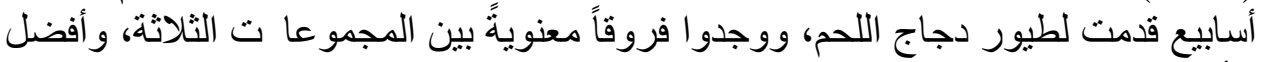

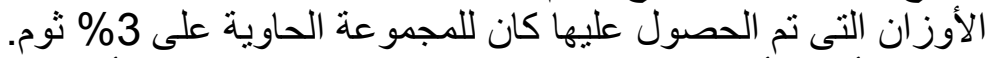

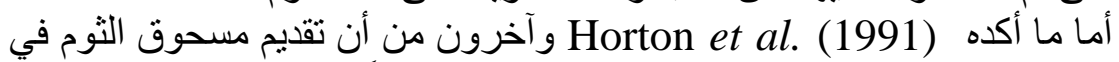
العلف بمستويات 1 أو 10 غ /كغ من العلف قد زادت حسابياً الكسب الوزني لطيور 
التسمين خلال الأيام 21 الأولى مقارنةً مع المجمو عة الثاهد فهو ينو افق مع نتائج هذه إنها

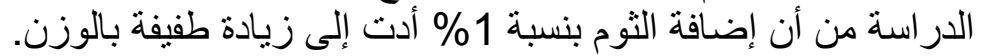

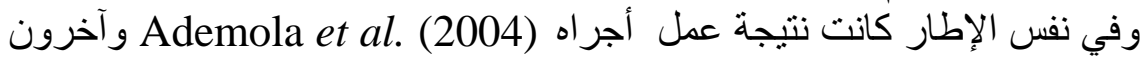

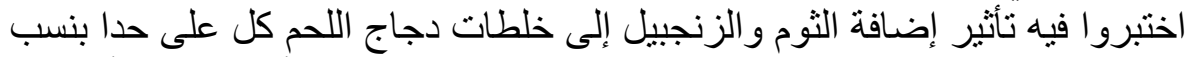

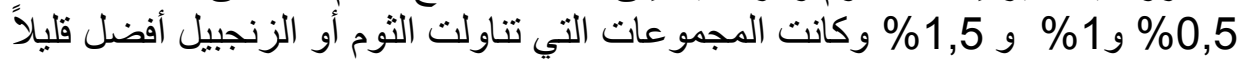

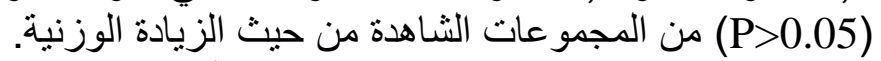

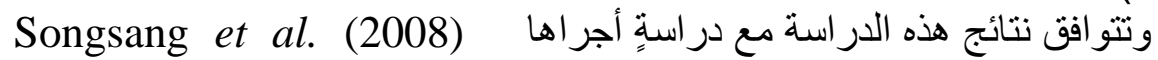

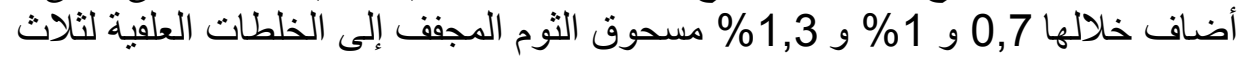

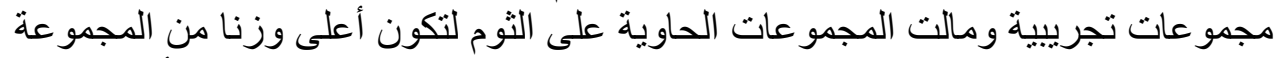

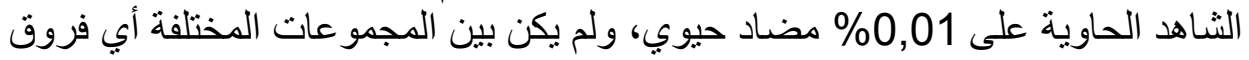
معنوية (P>0.05) في الزيادة الوزنية.

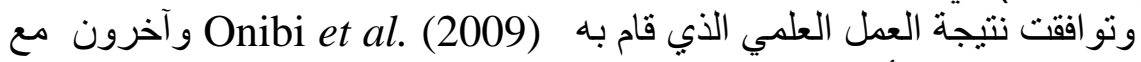

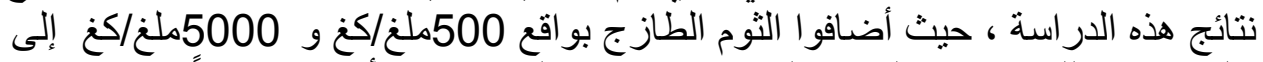

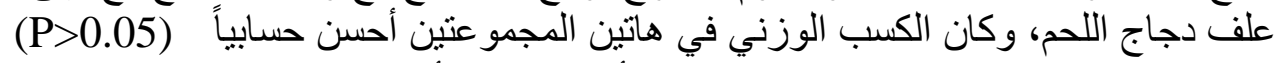

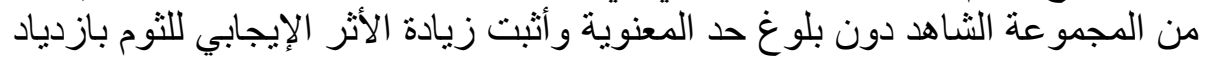

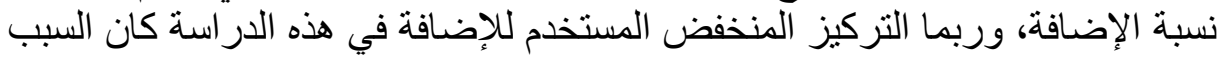

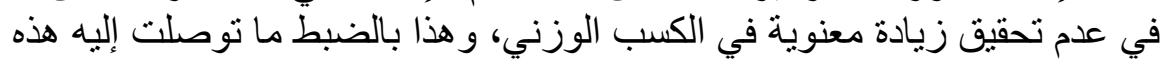

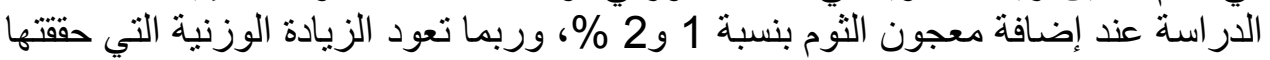

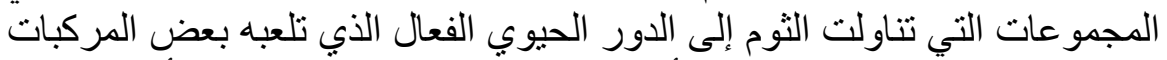

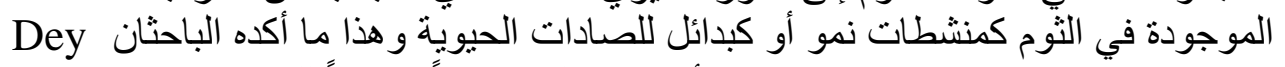

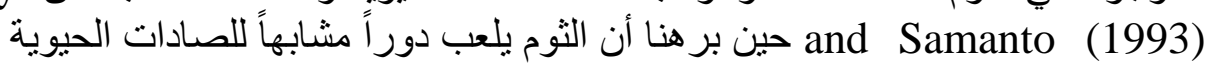

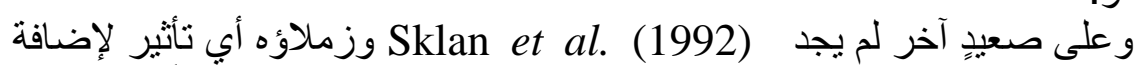

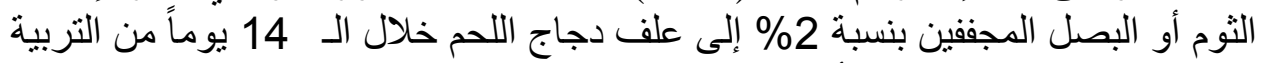

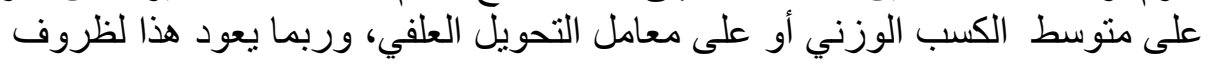

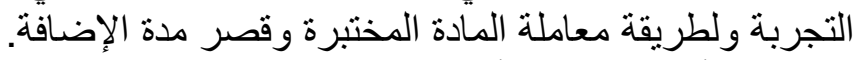

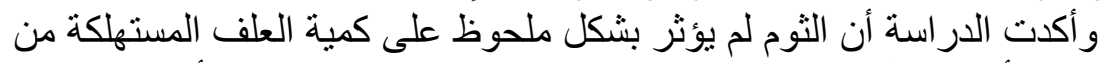

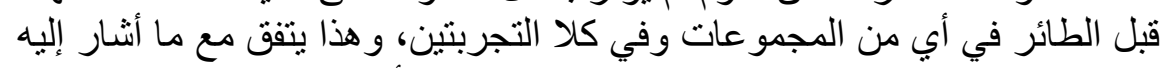

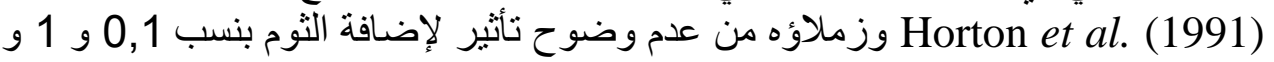

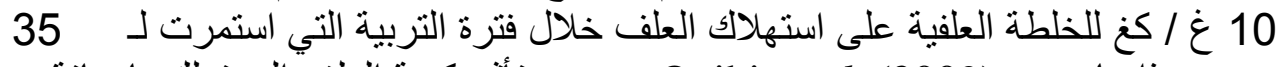

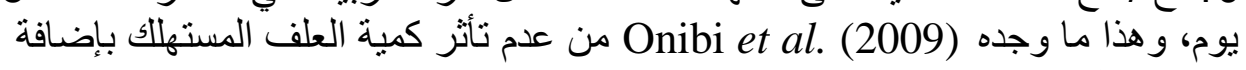
مسحوق الثوم الطازج.

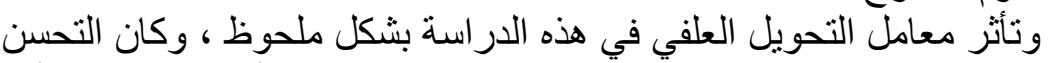

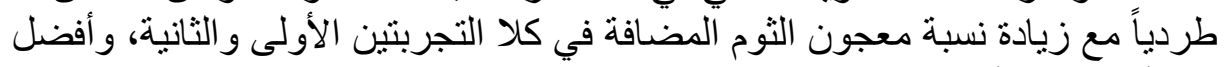
من المجمو عة الثاهد.

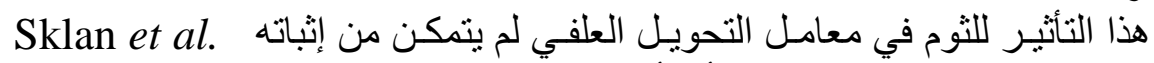

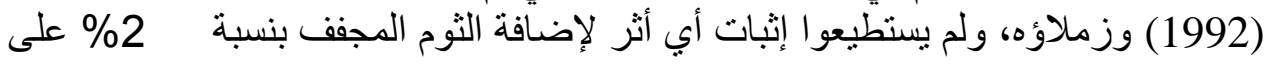




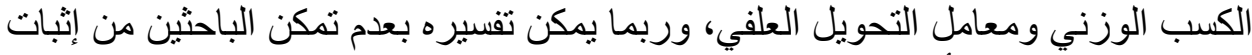

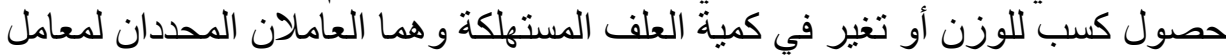

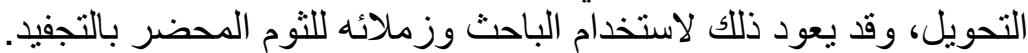

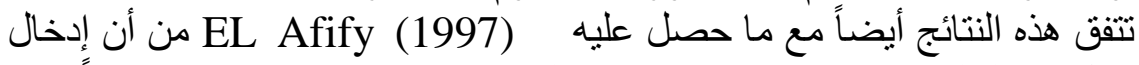

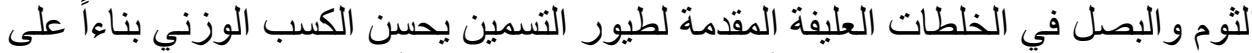

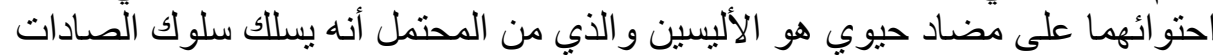

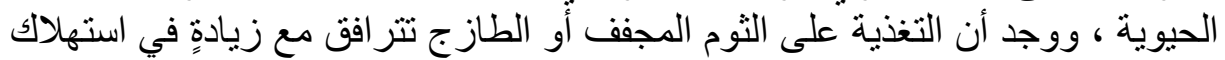

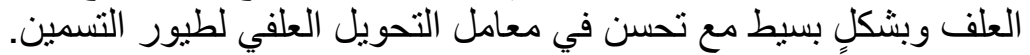

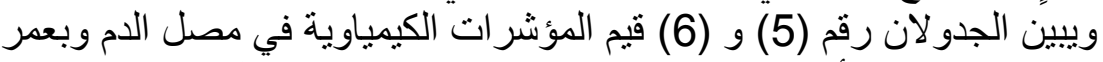

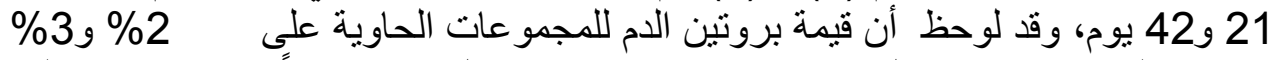

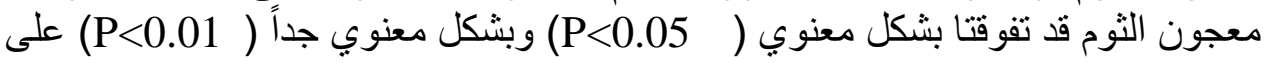

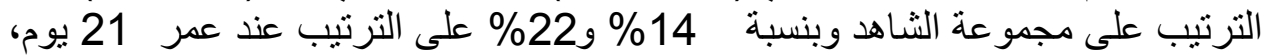

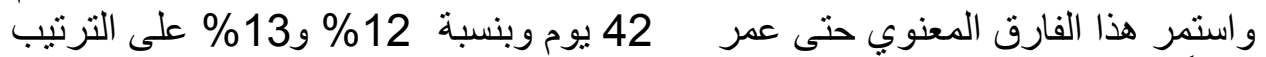

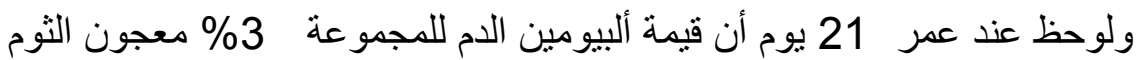

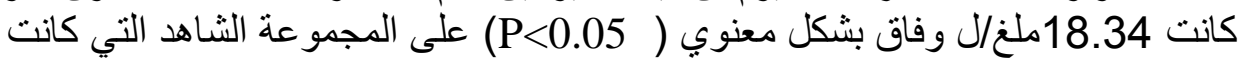

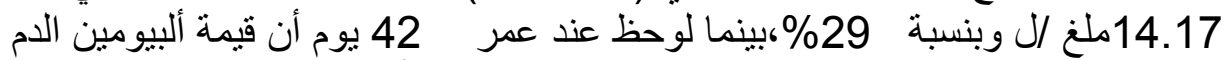

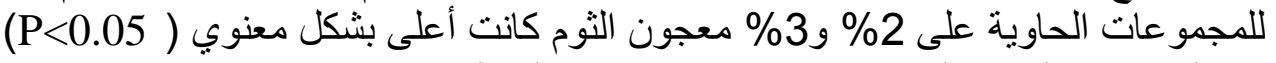

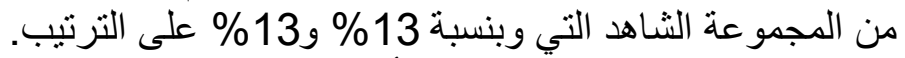

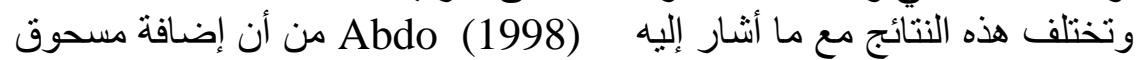

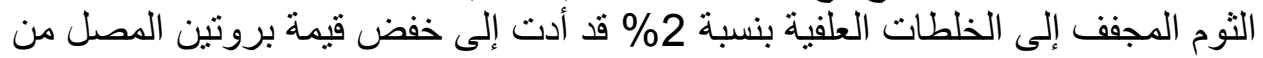
5,36 غ/دل وحتى 3,37 غ/دل بعمر 30 يو م ولم يلاحظ مثل هذا التغيير بالأعمار الأكبر

ولوحظ أن زيادة نسبة الإضافة تر افقت بزيادة مستوى بروتين المصل طردياً

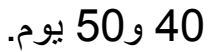

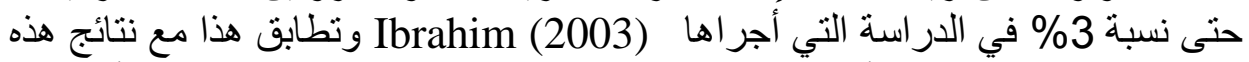

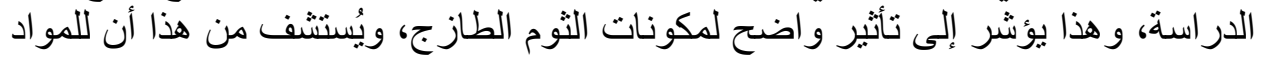

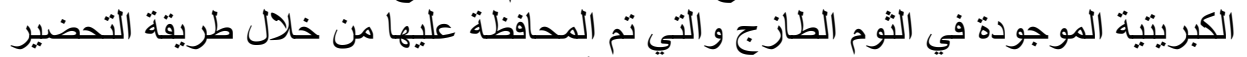

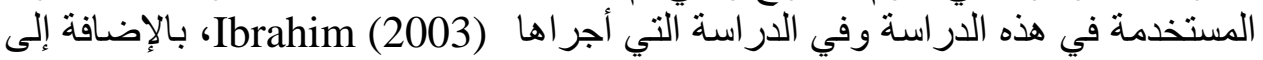

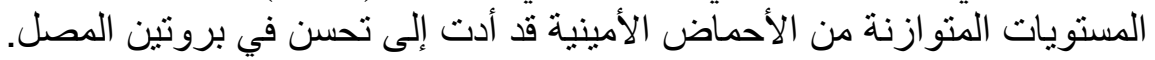

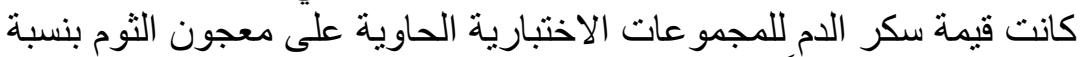

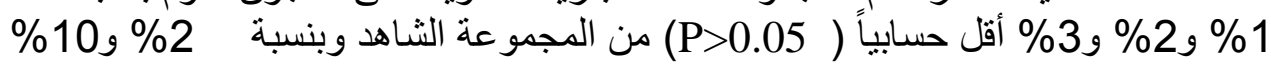

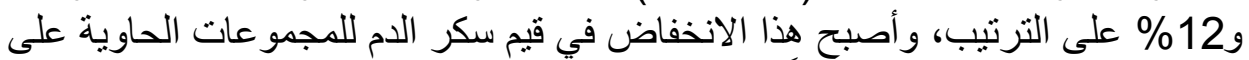

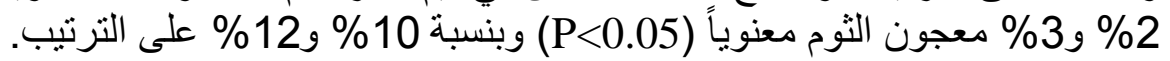

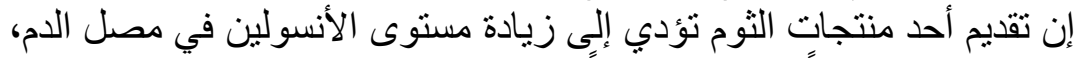

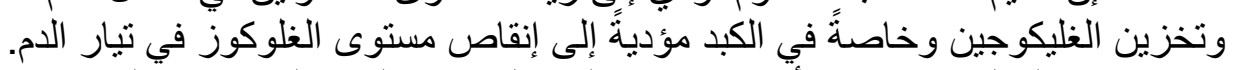

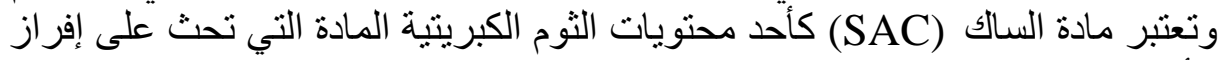
الأنسولين من البنكرياس (1996) Agusti and Sheela. 
ولوحظ بعمر 21 يوم أن قيمة الثحوم الثثلاثية للمجموعة الحاوية 3 3 14 معجون

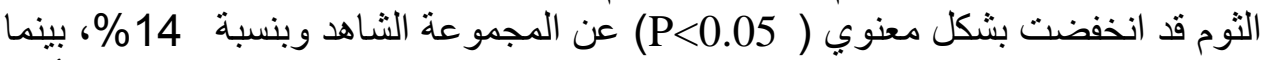

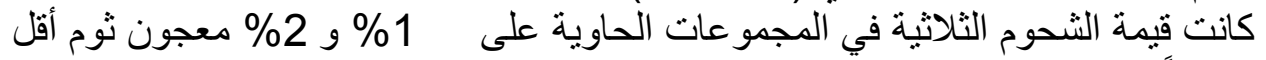

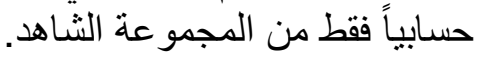

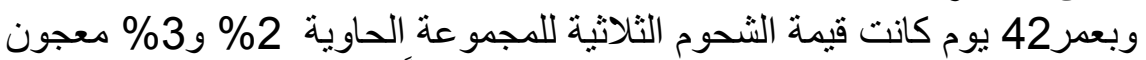

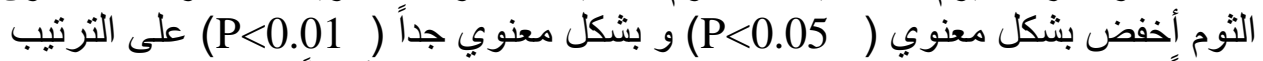

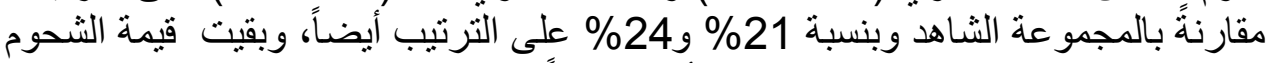

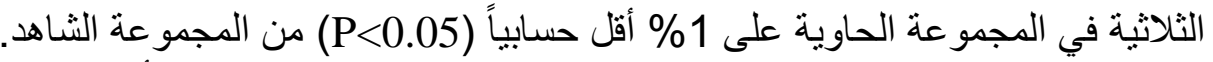

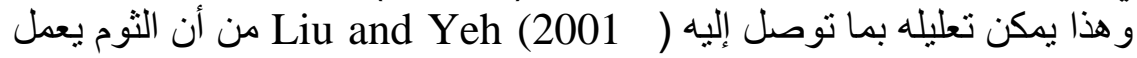

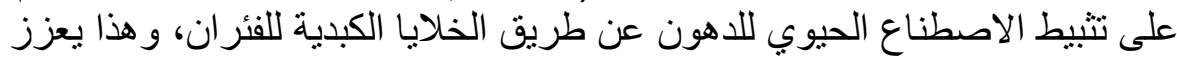

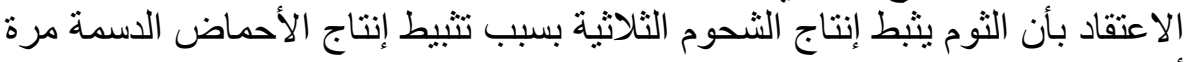

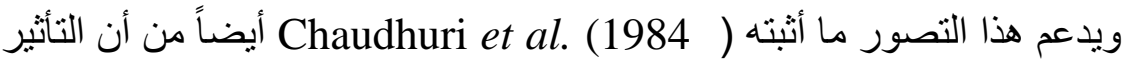
أخرى.

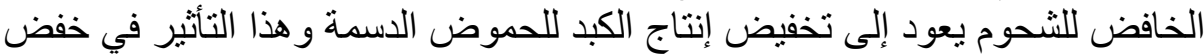

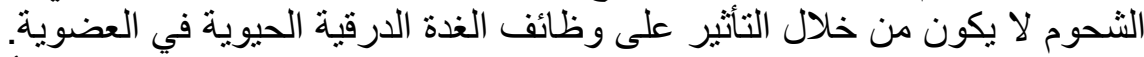

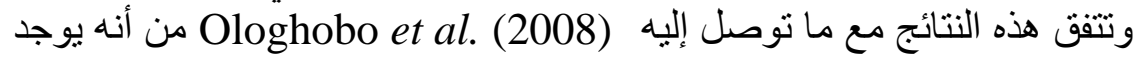

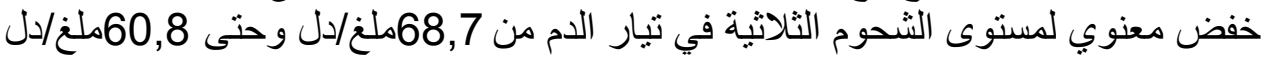

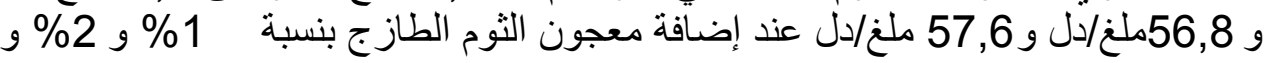

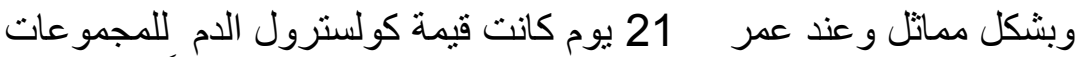

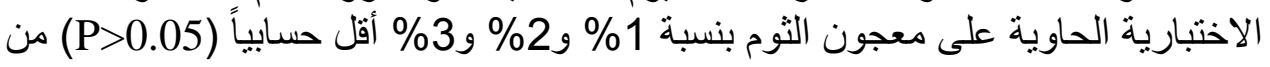

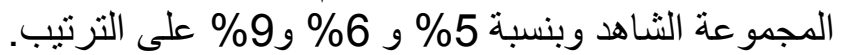

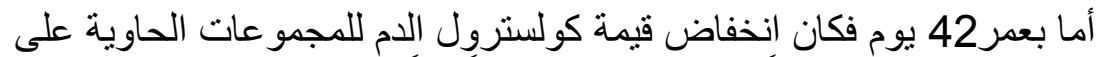

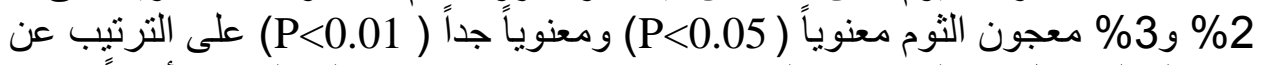

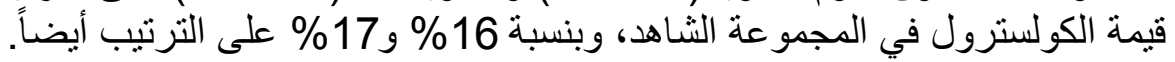
وكانت قيمة البروتينات الثحمية العالية الكثافة

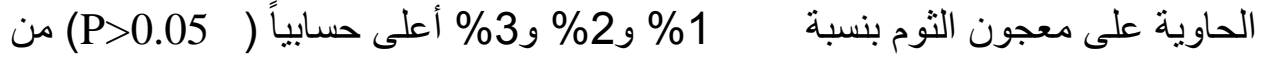

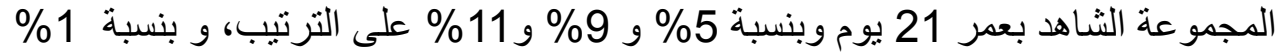

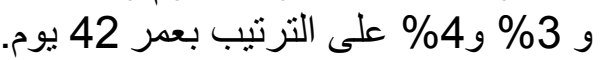

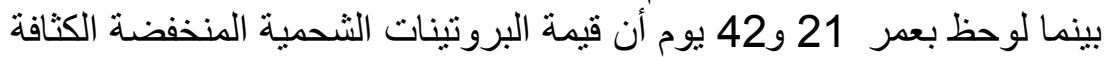
LDL

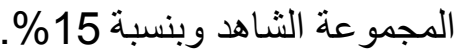

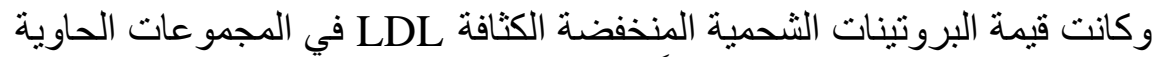

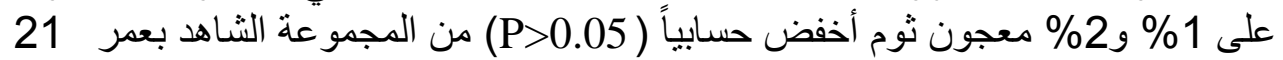

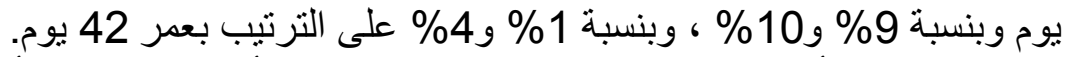

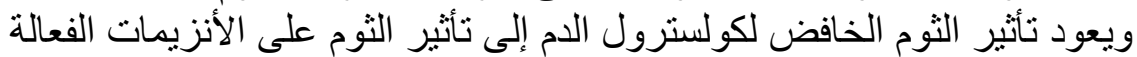

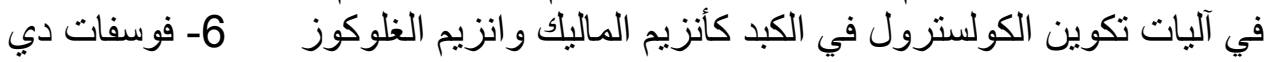


هيدروجينيز و أنظيم اختز ال HMG-CoA الذي يعتبر المفتاح الأنزيمي الذي يتحكم في

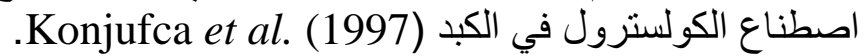
ولكن آليات تأثير الثوم الخافض للكولسترول ( Gebhardt (1995) لا تؤثر على

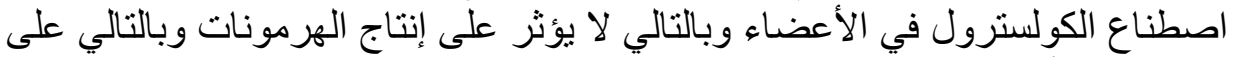
وظائفها في أعضاء الجسم المخترول في الاعنلفة

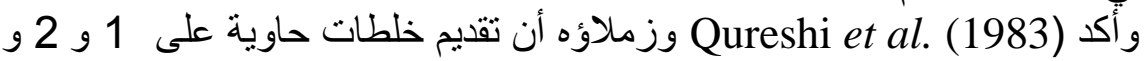
4 و 6 و 8 \% من معجون الثوم قد خفضت كولسترول المصل بنسبة 18 و 21 و و 21 و و 21 و

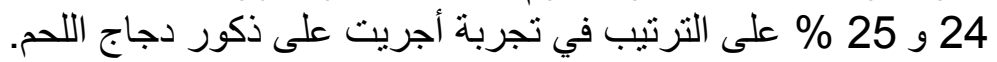

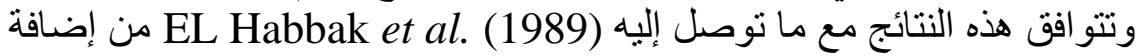

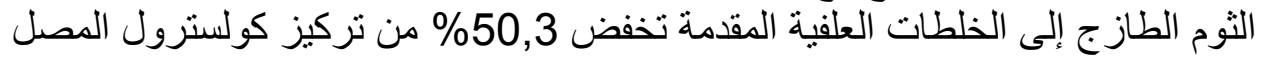
عند إضافة 4\% ثوم طاز جإ إلى الخلطة العلفية المقدمة للسمان الياباني.

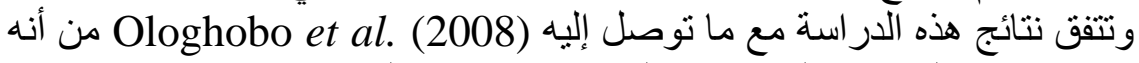
يوجد انخفاض معنوي لمستوى البروتينات الثحمية منخفضة الكثافة

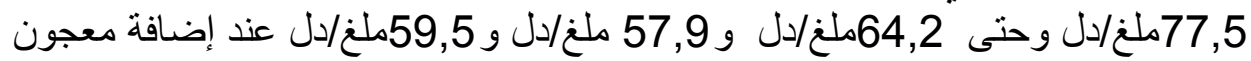

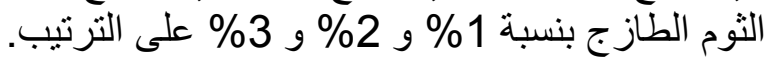

\section{CONCLUSIONS الاستنتاجات}

1 - وجود نأثير معنوي لإضافة معجون الثوم إلى الخلطات العلفية المقدمة لاجاج اللحم

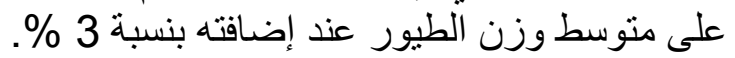
r

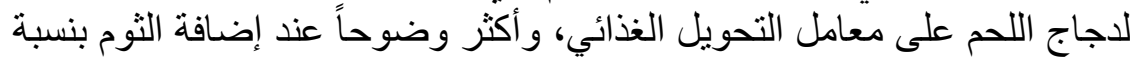
\%3 r - إن أفضل نسبة لإضافة معجون الثوم إلى الخلطات العلفية المقدمة إلى دجاج اللحم هي 30\%

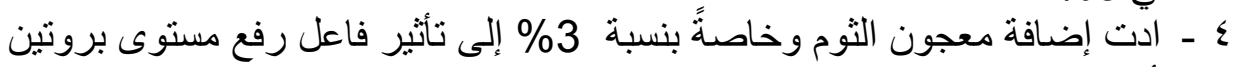

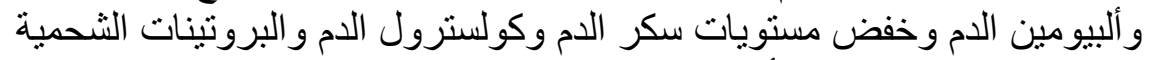
منخفضة الكثافة LDL، وأدت إلى رفع البروتينات الثحمية مرتفعة الكثافة HDL.

\section{REFERENCES}

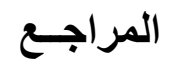

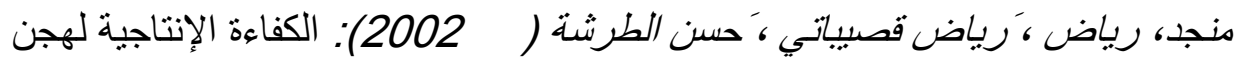

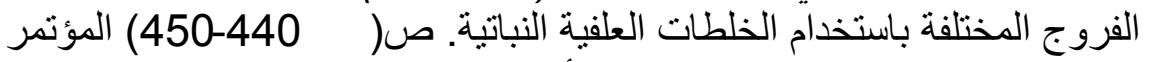

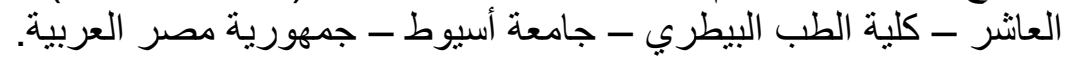

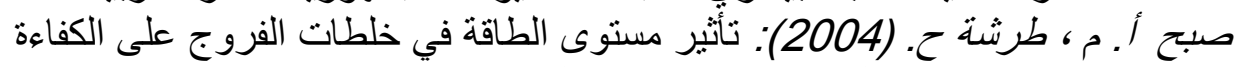
الإنتاجية ونو عية الذبيحة. مجلة جامعة البعث. 
Abdo, Z.M.A. (1998): The effect of using some natural growth promoter and fats on broiler performance and immunity. Ph. D. Thesis, Faculty of Agriculture, Animal Production department, Cairo University, Giza, Egypt.

Ademola, SG.; Farinu, GO.; Ajayi Obe, AO. and Babatunde, GM. (2004): Growth, haematological and biochemical studies on garlic- and ginger-fed broiler chickens, Moor Journal of Agricultural Research, 5, 2.

Agusti, K.T. and Sheela, C.G. (1996): Anti peroxide effect of S-allyl cysteine sulfoxide an insulin segretogogue in diabetic rats. Experientia 52: 115-120.

Ankri, S. and Mirelman, D. (1999): Antimicrobial properties of allicin from garlic. Microbes and Infection 1: 125-129.

Association of Official Analytical Chemists (A.O.A.C.) (2000): OfficiaL Methods of Analysis, $15^{\text {th }}$ edn. Association of Official Analytical Chemistsy Washington, V A,USA.

Ayoub, F.M. (1996): Using of onion and garlic in the rations of broiler chicks. M. Sc. Thesis, Anim. Prod. Dept. Fac. Agric El-Minia Univ.

Bergner, P. (1996): The Healing power of Garlic, pp. 3-26. Prima Publishing, Rocklin, CA.

Chaudhuri, BN.; Mukherjee, SK.; Mongia, SS. and Chakravarty, SK. (1984): Hypolipidemic effect of garlic and thyroid function. Biochim Acta. 43(7): 1045-7

Dey, A. and Samanto, A.R. (1993): Effect of feeding garlic as growth promoter in broiler. Indian J. of Anim. Health 32 (1): 17-19.

El-Afify, S.F. (1997): Nutritional studies on onion and garlic supplement to poultry feed. Ph. D. Thesis, Anim., Prod. Dep.

Fac. Agric., Ainshams Uuiv., Cairo -Egypt.

EL-Habbak, M.M.; Saleh, K.; Arbid, M.S.; Hegazi, A.G. and Sofy, H. (1989): Influence of garlic (Allium sativum L) on some biological and biochemical changes in Japanese quail with special reference to its hypocholesterolemic activity. Arch. Geflügel. 53(2): 73-79.

EL-Nawawi, G.H. (1991): Some of non conventional ingredients in broiler ration. M. Sc. Thesis, Ainm. Prod. Dep. Fac,. Agric., Ain-Shams Univ., Cairo -Egypt. 
Gebhardt, TR. (1995): Inhibition of cholesterol biosynthesis by garlic compounds. Berlin Garlic symposium of the $6^{\text {th }}$ Annual Phytotherapy Congrass, Oct.

Haq, A.U.; Meraj, K.A. and Rasool, S. (1999): Effect of Supplementing Allium Sativum (Garlig) and Azadirachta ndica (Neem) Leaves in Broiler Feeds on Their Blood Cholestrl, Triglycerides and Antibody Titre, international Journal of Agriculture and Biology 1560-8530/99/1, 3: $125-127$.

Horton, G.M.I.; Fennell, J. and Prasad, B.M. (1991): Effects of dietary garlic (Allium Sativum) on performance, carcass composition and blood chemistry changes in broiler chicken. Canadi. and Journal of Animal Science, 71: 939-942

Ibrahim, A. (2003): Effect of onion and/or garlic on growth performance and immunity of muscovy ducks broiler. Ph.D. Thesis, Anim. Nutrition and Clinical Nutrition, Fac. Vet. Med., Cairo, Univ.

Kabir, S.M.L. (2009): The Role of Probiotics in the Poultry Industry, Int. J. Mol. Sci. 2009, 10, 3531-3546; doi: 10.3390/ ijms10083531.

Khan, G. (1996): History of Garlic. In: Garlic: The Science and Therapeutic Application of Allium sativum L.and Related Species (Koch, H.P. and Lawson L.D., eds.), PP.25-36. Williams and Wilkins, New York, NPP.25-36. Williams and Wilkins, New York, N.

Konjufca, V.H.; Pesti, G.M. and Bakalli, R.I. (1995): The influence of dietary garlic powder on the cholesterol content of broiler chickens. Poultry Sci., Supplement 1, Abstr. No, 43: page 15.

Konjufca, V.H.; Pesti, G.M. and Bakalli, R.I. (1997): Modulation of cholesterol levels in broiler meat by dietary garlic and copper: Poultry Science 76: 1264-1271.

Lawson, L.D. (1998): Garlic: review of its medical effect and indicatedactive compounds. In: Phytonedicines of Europe. Chemistry and Biological Activity. ACS Symposium Series, Washington, DC. 
Liu, Y. and Yeh, Y.Y. (2001): Inhibation of cholesterol biosynthesis by organo sulfur compound derived from garlic. Lipds 35: 147-203.

Moyers, S. (1996): Garlic in health, history and world cusine. pp 1-36 Sun Coast Press. st. pertersbury, Fl. and boild.

Ocak, N.; Erener, G.; Burak Ak, F.; Sungu, M.; Altop, A. and Ozmen, A. (2008): Performance of broilers fed diets supplemented with dry peppermint (Mentha piperita L.) or thyme (Thymusvulgaris L.) leaves as growth promoter source, Czech J. Anim. Sci., 53, (4): 169-175.

Ologhobo, A.D.; Adebiyi, F.G. and Adebiyin, O.A. (2008): Effect of long term feeding of raw andsun-dried garlic (allium sativum) on performance and lipid metabolism of broiler chicks, J.R. Coll. Physicians Lond. 30: 329-334.

Onibi, GE.; Adebisi, OE.; Fajemisin, A.N. and Adetunji, A.V. (2009): Response of broiler chickens in terms of performance and meat quality to garlic (Allium sativum) supplementation, African Journal of Agricultural Research 4, 5: 511-517.

Parr, J.F. and Summers, J.D. (1991): The effect of minimizing amino acid excesses in broiler diets. Poultry Sci. 70: 1550-1558.

Qureshi, A.A.; Din, Z.Z.; Abuirmeileh, N.; Burger, W.C.; Ahmad, Y. and C.E. (1983): Suppression of avian hepatic lipid metabolism by solvent extracts of garlic: Impact on serum lipids. J. Nutr., 113: 1746-1755.

Reuter, H.D.; Koch, H.P. and Lawson, L.D. (1996): Therapeutic effect of garlic and its preparations. In: Garlic, 2nd ed. (Koc, H. P. \& Lawson, L. D., eds.), PP. 135-162. Williams and Wilkins, London UK.

Schneider, B.H. and Flatt, W.P. (1975): The Evaluation of Feed through Digestibility Experiments The University of Georgia Press. Athens, USA.

Sklan, D.; Berner, Y.N. and Rabinowitch, H.D. (1992): The Effect of Dietary Onion and Garlic on Hepatic Lipid Concentrations and Activity of Antioxidative Enzymes in Chicks: J. Nutr. Biochem., 3: 322-325. 
Songsang, A.; Suwanpugdee1, A.; Onthong, U.; Reawadee, S.; Pimpontong, P.; Chotipun, S. and Promgerd, W. (2008): Effect of Garlic (Allium sativum) Supplementation in Diets of Broilers on Productive Performance, Meat Cholesterol and Sensory Quality,. Conference "Competition for Resources in a Changing World: New Drive for Rural Development" Tropentag, October 7-9, Hohenheim Abst.

SPSS Statistical 17.0 (2008): Statistical Package for Social SciencesVersion 17.0. Computer software 17.0, SPSS Inc., Headquarters. Wacker Drive, Chicago, lllinois 60606, USA. 
Assiut Vet. Med. J. Vol. 57 No. 129 April 2011 
Assiut Vet. Med. J. Vol. 57 No. 129 April 2011 
